\title{
The developmental impact of prenatal stress, prenatal dexamethasone and postnatal social stress on physiology, behaviour and neuroanatomy of primate offspring: studies in rhesus macaque and common marmoset
}

\author{
Christopher R. Pryce • Yves Aubert • Claudia Maier • \\ Peter C. Pearce $\cdot$ Eberhard Fuchs \\ Received: 21 April 2010 /Accepted: 25 July 2010 /Published online: 1 September 2010 \\ (C) The Author(s) 2010. This article is published with open access at Springerlink.com
}

\begin{abstract}
Rationale Exposure of the immature mammalian brain to stress factors, including stress levels of glucocorticoids, either prenatally or postnatally, is regarded as a major regulatory factor in short- and long-term brain function and, in human, as a major aetiological factor in neuropsychiatric disorders. Experimental human studies are not feasible and animal studies are required to demonstrate causality and elucidate mechanisms. A number of studies have been conducted and reviewed in rodents but there are relatively few studies in primates.

Objectives Here we present an overview of our published studies and some original data on the effects of: (1) prenatal
\end{abstract}

C. R. Pryce $\cdot$ Y. Aubert $\cdot$ C. Maier

Behavioural Neurobiology Laboratory,

Swiss Federal Institute of Technology Zürich,

Schwerzenbach, Switzerland

P. C. Pearce

Biomedical Sciences Department,

Defence Science and Technology Laboratory,

Porton Down,

Salisbury, Wiltshire, UK

E. Fuchs $(\square)$

Clinical Neurobiology Laboratory, German Primate Center,

Kellnerweg 4,

37077 Göttingen, Germany

e-mail: efuchs@gwdg.de

C. R. Pryce

Clinic for Affective Disorders and General Psychiatry,

University Hospital Zürich,

Zürich, Switzerland

Y. Aubert

Division of Medical Pharmacology, LACDR, Leiden University,

Leiden, the Netherlands stress on hypothalamic-pituitary-adrenal (HPA) re/activity and hippocampus neuroanatomy in juvenile-adolescent rhesus macaques; (2) prenatal dexamethasone (DEX) on HPA activity, behaviour and prefrontal cortex neuroanatomy in infant-adolescent common marmosets; (3) postnatal daily parental separation stress on HPA re/activity, behaviour, sleep and hippocampus and prefrontal cortex neuroanatomy in infant-adolescent common marmoset.

Results Prenatal stress increased basal cortisol levels and reduced neurogenesis in macaque. Prenatal DEX was without effect on HPA activity and reduced social play and skilled motor behaviour in marmoset. Postnatal social stress increased basal cortisol levels, reduced social play, increased awakening and reduced hippocampal glucocorticoid and mineralocorticoid receptor expression in marmoset.

Conclusions Perinatal stress-related environmental events exert short- and long-term effects on HPA function, behaviour and brain status in rhesus macaque and common marmoset. The mechanisms mediating the enduring effects remain to be elucidated, with candidates including increased basal HPA function and epigenetic programming.

Keywords Glucocorticoid receptor · Hippocampus · HPA axis · Mineralocorticoid receptor - Neurogenesis ·

Neuropsychiatric disorders $\cdot$ Prefrontal cortex $\cdot$ Skilled motor behaviour $\cdot$ Sleep $\cdot$ Social play

\section{Introduction}

For the neuropsychiatric disorders there is evidence from epidemiology, including some prospective studies, that prenatal (foetal) and/or postnatal (infant-child) environmental 
factors are associated substantially with aetiology. Examples for association between prenatal events and neuropsychiatric disorders are stress and schizophrenia (McDonald and Murray 2000), and glucocorticoid over-exposure and attention deficit hyperactivity disorder (Talge et al. 2007). Examples for association between postnatal events and neuropsychiatric disorders are infant neglect or abuse and post-traumatic stress disorder (Pervanidou and Chrousos 2007) and depression (Kendler et al. 2002).

With regard to prenatal aetiological factors that might increase the developmental and adult risk of neuropsychiatric disability, glucocorticoid hyper-exposure is considered to be a major candidate (Lupien et al. 2009; Rice et al. 2010). That too much transfer of maternal cortisol (corticosterone in rodents) to the foetal compartment can have deleterious consequences appears to be indicated by the placental function of synthesis of enzymes to metabolise cortisol into less active forms, such as cortisone, thereby affording some protection to the foetus (Seckl 1997; 2004). Nevertheless, subsequent to maternal stress, hormone alterations as well as other physiological changes appear to be able to inactivate the placental buffer and alter foetal development (Fujii et al. 2003; Rees et al. 1999). Foetal glucocorticoid hyper-exposure can occur in the context of environmental stress during pregnancy leading to increased activity in the maternal axis between hypothalamusmodulated by input from several other brain regions including hippocampus, amygdala and prefrontal cortexpituitary and adrenal gland, and thereby to increased cortisol levels that could also access the feto-placental unit. It can also occur in the context of the clinical practice of synthetic glucocorticoid administration for certain obstetric conditions, including pregnancies at risk for premature birth where the mother is administered glucocorticoid with the aim of increasing foetal lung exposure to glucocorticoid and thereby stimulating lung maturation (Crowley 2000); synthetic glucocorticoids are given during gestation for several other clinical conditions of the mother or foetus, including allergies, asthma and congenital adrenal hyperplasia (Tegethoff et al. 2009). Human studies of the inter-relationships between prenatal stress or prenatal glucocorticoid hyperexposure and offspring hypothalamic-pituitary-adrenal (HPA) axis and neurobehavioural function provide evidence of, for example, reduced HPA re/activity in infants (Tegethoff et al. 2009) and disturbances in neurological and cognitive development (Talge et al. 2007). However, the vast majority of human studies are, by necessity, descriptive and therefore cannot demonstrate causality or identify the basic mechanisms that underlie pathophysiological processes during development or in adulthood. In rat, manipulative studies of prenatal stress exposure or administration to gravid females of adrenocorticotrophic hormone (ACTH) or of the synthetic glucocorticoid dexamethasone (DEX), have dem- onstrated, for example, that prenatal DEX delays maturation of neurons and inhibits neurogenesis and prenatal stress increases anxiety in adulthood (Lupien et al. 2009). In rhesus macaque, prenatal DEX leads to degeneration of hippocampal neurons and reduced hippocampal volume in adolescence (Uno et al. 1990). A major candidate for a mechanism whereby prenatal glucocorticoid hyper-exposure (and other prenatal events) can mediate long-term effects is epigenetic programming of gene expression: the product and effects of the gene could be permanently amplified or reduced, thereby continuously mediating molecular and cellular processes in the central nervous system (CNS) (Seckl 2008).

With regard to postnatal aetiological factors that can increase the developmental and adult risk of neuropsychiatric disability, stress related to the social relationship between the developing infant and the primary caregiver (s) is the major candidate. Maternal care is the defining characteristic of the mammalian infant's postnatal experience, and takes the form of nursing, stimulation and buffering from environmental stressors (Pryce et al. 2005). In humans, retrospective epidemiological and clinical studies have demonstrated that parental loss due to death or separation, parent-infant emotional and physical neglect, and emotional and physical abuse, predict developmental and adulthood changes in HPA axis and neurobehavioural function, and the risk of adulthood depression (Heim et al. 2004; Kendler et al. 2002). In monkeys, the manipulation of rearing the infant in the absence of its mother, as conducted by Harlow in rhesus macaques, has demonstrated the considerable need of primate infants for maternal care beyond nursing, for normal development (Ruppenthal et al. 1976). In rat, studies of repeated maternal separation have demonstrated long-term effects on HPA function, hippocampal and prefrontal cortex neuroanatomy, and anxiety and memory (Ladd et al. 2004; Pryce and Feldon 2003). Induced and spontaneous differences in rat maternal care are associated with epigenetic effects in adult offspring at the glucocorticoid receptor (Weaver et al. 2004), indicating that epigenetic programming might also be a major mediating mechanism between postnatal stress and long-term risk of neurobehavioural dysfunction.

There are a number of reasons why it is essential to complement rodent studies of the developmental consequences for offspring of prenatal or postnatal stress and prenatal glucocorticoid over-exposure, with studies in monkeys. With respect to foetal biology, placentation is more invasive (haemochorial) in simian primates (monkeys, apes, humans) than in rodents; that is, the feto-placental tissues are bathed directly in maternal blood without an intervening cellular barrier (Clancy 2009). It has been demonstrated that fatty acid (but not protein or carbohydrate) transfer from the mother to the 
foetus is greater in species with more invasive placentation (Elliot and Crespi 2008) and potentially, therefore, increases in glucocorticoid and other stress factor levels in the maternal circulation could also lead to more marked increases in these factors in the foetal circulation in species with more invasive placentation. Relative to body size, gestation is prolonged in the simian primates relative to rodents, and, in line with the "pacemaker" function of the brain in foetal development, relative brain size at birth is markedly increased in the simian primates relative to rodents (Martin 1990). Postnatal brain growth is reduced in monkeys and apes relative to that in rodents, but here the human brain with its marked postnatal brain growth is more rodent-like than primate-like (Martin 1990). Postnatal development in monkeys, apes and traditional human societies is characterised by several weeks/months of continuous physical contact of the single infant (or in some species twins) with the mother, in contrast to rodents where large litters are maintained in a nest and experiencing periods of absence of maternal care from birth onwards is the norm (Pryce et al. 2005).

Here we present an overview of some of our own studies, published and original, into the evidence for long-term consequences of perinatal events on offspring psychoneuroendocrine development in monkeys. Specifically, we present studies of developmental consequences of: (1) Prenatal stress for HPA re/activity and hippocampus neuroanatomy in juvenile rhesus macaques. (2) Prenatal dexamethasone for HPA activity, behaviour and prefrontal cortex neuroanatomy in infant-adolescent common marmoset. (3) Postnatal daily parental separation stress for HPA re/activity, behaviour, sleep, and hippocampus and prefrontal cortex neuroanatomy in infantadolescent common marmoset. Each of these studies is directly relevant to a general framework of perinatal stress-related events and long-term psychoneuroendocrine development in nonhuman primates. Given that the separate studies deal with the effects of different manipulations, experienced at different developmental time points, to some extent on different end-points, and in different species, then the emphasis of this overview is on collating the evidence we have obtained for the nature and direction of effects of perinatal stress/glucocorticoid over-exposure on offspring development in the two primate species most commonly studied in the laboratory. Given the heterogeneity of the studies, then meaningful integration of the evidence obtained to yield emergent general conclusions is somewhat limited. Nonetheless, where appropriate, major findings of each study in terms of long-term effects on HPA axis, behaviour or neuroanatomy, are integrated with either the findings of the other studies presented or with relevant findings from rodent and human studies, in a general discussion.
Developmental consequences of prenatal stress for HPA function and hippocampus in the rhesus macaque

In a study conducted in rhesus monkeys at the Harlow Primate Laboratory, University of Wisconsin, Madison, WI, USA (for details see (Coe et al. 2003)) we assessed the impact of equivalent periods of maternal disturbance experienced either early or late in gestation on the offspring hippocampus, a sensitive and critical area of the developing brain (Koehl et al. 1999; Takahashi 1998). Given that one important function of the hippocampus is its involvement in the regulation of the HPA axis, we hypothesised that rhesus monkeys from disturbed pregnancies might reveal signs of cortisol hyperactivity comparable to that seen in rats that were stressed early in the postpartum period (Meaney et al. 1992; Plotsky and Meaney 1993b; Weinstock 1997). Also in rats, maternal stress during the last week of pregnancy affects hippocampal neurogenesis in the pups (Lemaire et al. 2000), but this finding has not been replicated in nonhuman primate infants. We therefore investigated to what extent foetal disturbance might influence the ability of the dentate gyrus of the hippocampal formation to generate new cells later in life. If prenatal stress in rhesus monkeys alters the set point for cell growth in the hippocampus, it may indirectly explain findings from many retrospective studies in humans suggesting that learning disabilities and even mental disorders might be programmed in the foetal period (Brown et al. 2000; Clements 1992; Huttunen and Niskanen 1978; Myhrman et al. 1996; van Os and Selten 1998; Watson et al. 1999).

Rhesus monkey infants were generated from three types of pregnancies. Control animals from undisturbed, normal pregnancies were compared with subjects that had been disturbed for 6 weeks during the 24-week pregnancy, either early or late in gestation. The pregnant female was acutely disturbed 5 days per week, by being moved to a darkened test room. While located there for $10 \mathrm{~min}$ in a small transport cage, the animal was intermittently aroused with an acoustical startle protocol (three 1-s broadcasts of a $110 \mathrm{db}$ horn, randomly at 1-4-min intervals). Earlier studies from the laboratory in Madison using the same paradigm demonstrated that it significantly elevates cortisol above the normal level for pregnant monkeys, and can affect the infant's behavioural reactivity and immunity later in life. Specifically it has been shown that disturbance of the pregnant females using this method results in offspring with immature neuromotor reflexes at birth, greater emotionality as infants, and lymphocyte responses that were still abnormal at 2 years of age (Clarke and Schneider 1993; Coe et al. 2002; Schneider et al. 1999). In the present experiment the early stress period was days 50-92 postconception, and the late stress period was days 105-147 post-conception, of the 165-day gestation period. Before 
and after these 6 week manipulations, the pregnant females lived undisturbed in their home cages until the natural birth of their infants (Fig. 1). After birth, the infants were reared normally by the mother and observations of the maternal behaviour did not indicate that the prenatally stressed infants were treated differently from control infants. At 7 months of age, the infants were transferred into small social groups.

The behavioural, endocrine and neuroanatomical data are summarised in Fig. 2: Juvenile subjects from the early stress pregnancies performed significantly less exploration than controls. To characterise the activity of the HPA axis, plasma cortisol levels were determined under basal conditions and after a $12 \mathrm{~h}$ overnight dexamethasone treatment (DEX) at the age of 2.0-2.5 years. Rhesus monkeys from the early stress and late stress pregnancies had significantly higher basal cortisol levels than controls. Twelve hours after DEX administration, both the early stress and late stress monkeys had significantly higher cortisol levels than controls, suggesting that their HPA axis was relatively insensitive to DEX suppression which, given the low blood-brain barrier permeability of DEX, would be expected to be exerted primarily at the level of the glucocorticoid receptors expressed by the pituitary gland. Clearly, the experience of maternal stress during pregnancy results in the offspring having a different set point for the HPA axis. In turn, these findings indicate that chronic changes in adrenocortical hormone levels could be involved in mediating the chronic maternal stress effects on the offspring (Dodic et al. 2002; Nyirenda and Seckl 1998; Wadhwa et al. 2001).

Several months after the assessment of HPA activity (age 2.5-3.0 years), the monkeys received thymidine analogue 5-bromo-2'-deoxyuridine (BrdU) to label dividing cells and to evaluate the treatment effects on the generation of new neurons. Three weeks following the BrdU application the animals were perfused to obtain the brains for histological and stereological analysis, including the determination of the hippocampal volume. Quantitative analysis of the BrdU-labelled cells in the dentate gyrus revealed that maternal disturbance during either early or late pregnancy resulted in a dramatic decrease (32\%) in density compared with the undisturbed controls (Fig. 2), with no differential effect found with respect to the timing of the maternal stress during pregnancy. Interestingly, there was a significant negative correlation $(P<0.05$; all subjects combined $)$ between plasma cortisol levels after the DEX suppression test and the number of BrdU-positive cells in the dentate gyrus.

Adult hippocampal neurogenesis is considered to be an important contributor to the plasticity of adult neural circuitry. The functional role of the newly generated granule cells is still under discussion, but several studies suggest that they can play an active role in the formation of certain types of hippocampus-dependent memory (Shors et al. 2001, 2002). In addition, several recent studies have suggested that altered rates of adult neurogenesis may contribute to the aetiology or pathophysiology of some stress-related psychiatric illnesses, especially to mood disorders (Czeh et al. 2001; Fuchs et al. 2006; Lucassen et al. 2010).

Post mortem volumetry of the hippocampal formation revealed that prenatal stress resulted in a mild, but statistically significant decrease in the hippocampal volume (Fig. 2). Again, as for cortisol levels, the timing of the disturbance during pregnancy did not have a differential effect (mean reduction $12 \%$ in monkeys from the early stress group and $10 \%$ in the late stress monkeys, as compared with controls). Although this reduction in hippocampal volume might seem modest, it should be
Fig. 1 Schematic showing the major developmental life-history stages of the rhesus macaque (a) and the common marmoset (b). Please note that the scale for the rhesus macaque is given in years and the one for the common marmoset in weeks

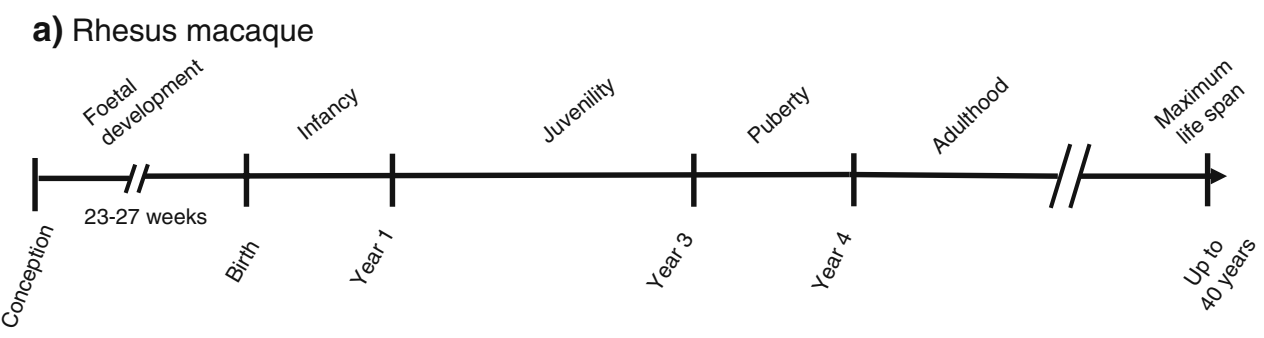

b) Common marmoset

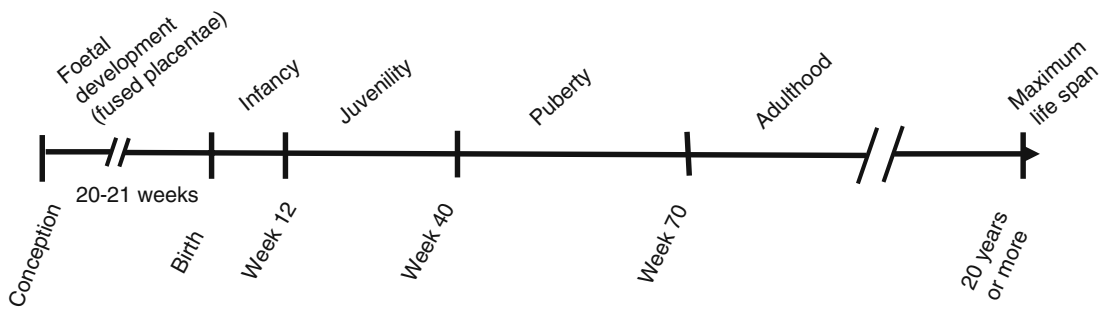


Fig. 2 Effects of prenatal stress, both early $(E P N S)$ and late $(L P N S)$ in pregnancy on behaviour, cortisol titres in basal condition and after DEX stimulation, on neurogenesis and hippocampal volume in rhesus macaque offspring generated from stressed and control pregnancies. Values are mean $\pm \mathrm{SEM} ;{ }^{*} p<0.05$, significantly different from control monkeys (with modifications from Coe et al. 2003)

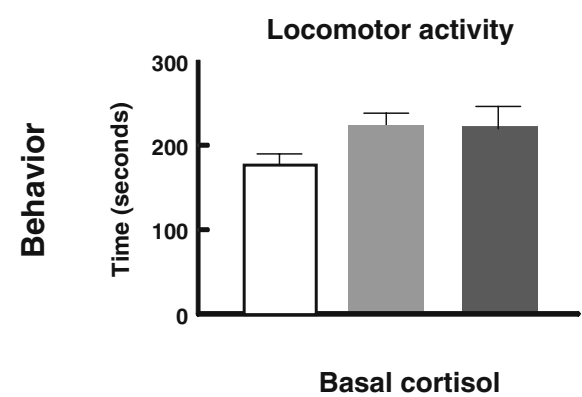

Exploration
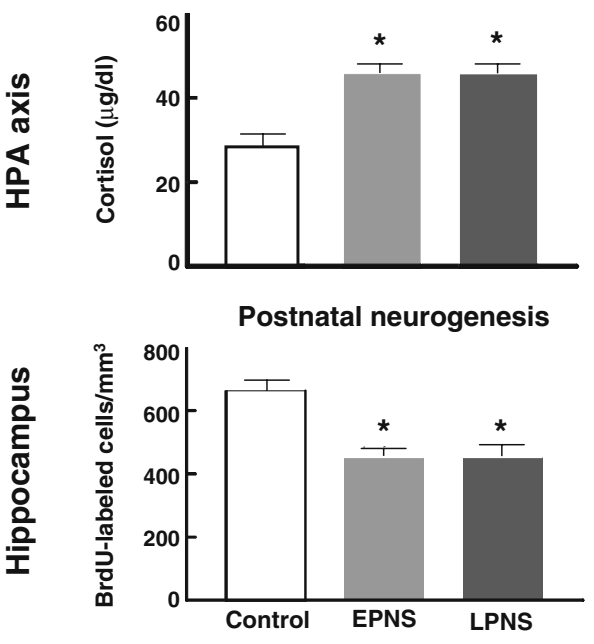
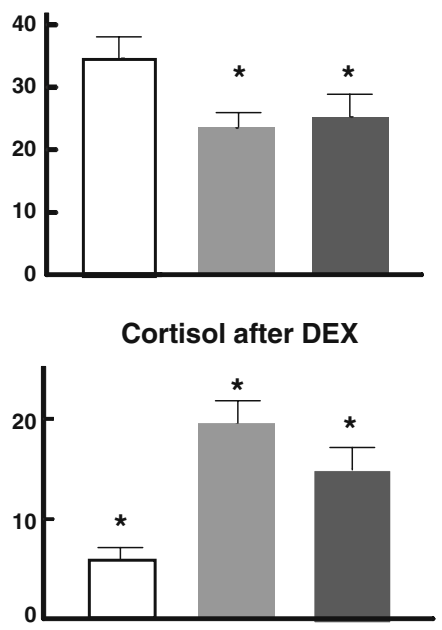

Hippocampal volume

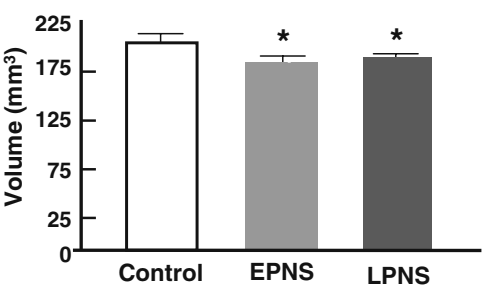

noted that MRI analyses revealing a similar percentage of hippocampal shrinkage in psychiatric patients has raised considerable concern (e.g. Bremner et al. 2000; Gur et al. 2000). It is of further interest that a recent clinical study suggested that the occurrence of smaller hippocampi may constitute a risk factor for the development of stress-related psychopathology (Gilbertson et al. 2002). Thus, it is conceivable that individuals with a disturbed structural neuronal plasticity due to prenatal stress might be at greater risk for developing psychiatric illnesses. Of course, in addition to structural changes, maternal stress may induce an imbalance in numerous other factors, such as excitatory amino acid neurotransmitters, neurotrophins, and cortictrophin releasing hormone (CRH), in the foetal CNS (Avishai-Eliner et al. 2002).

Developmental consequences of prenatal dexamethasone exposure for HPA function, behaviour and CNS in the common marmoset

The common marmoset and some other New World monkeys exhibit relative glucocorticoid insensitivity (Westberry et al. 2006), a point which is obviously important here but which can largely be accommodated by appropriate experimental design, as reviewed in the Discussion.

The effects of prenatal exposure to DEX on marmoset development were studied from age P 2 until postnatal week 64 (Hauser et al. 2007, 2008). The study was conducted with 12 breeding pairs of common marmosets, with 4 pairs each contributing twins to the following treatment groups: Vehicle (VEH): pregnant females with foetuses at an estimated week 7 of gestation were restrained once daily for 7 days and administered syrup per os, and this was repeated at week 13; Early DEX (EDEX): pregnant females with foetuses at an estimated week 7 of gestation were restrained daily and administered $5 \mathrm{mg} / \mathrm{kg}$ DEX in syrup per os, and at estimated week 13 were administered syrup; Late DEX (LDEX): pregnant females with foetuses at an estimated week 7 of gestation were restrained daily and administered syrup per os, and at estimated week 13 were administered $5 \mathrm{mg} / \mathrm{kg}$ DEX in syrup per os. This yielded 24 subjects, 8 per group, with the VEH group comprising 4 males, 4 females, the EDEX group 5 males, 3 females, and the LDEX group 5 males, 3 females (Hauser et al. 2007). Although there are no available data for the common marmoset, comparison with data from the rhesus macaque and human (Levitt 2003) suggest that treatment in the late first trimester is likely coincident with a maturational stage of high neurogenesis and gliogenesis and high cell migration in this primate and therefore a putative sensitive period for inducing acute central effects with longterm consequences. Treatment in the late second trimester is likely coincident with the maturational stage analogous to that at which the human foetus at risk for preterm delivery 
is exposed to synthetic glucocorticoids as a prophylactic clinical measure, and therefore of particular translational relevance. The administration of DEX was associated with restraint of the pregnant female; therefore maternal stress responses to restraint imparting exposure of the foetuses to maternal stress factors could have been a confounding factor in this study. In this respect it would have been beneficial to include an unrestrained control group as well as the VEH group. One mitigating factor was that the females had considerable prior experience of restraint; for example, they were restrained for blood sampling on a weekly basis for several months prior to the study.

In terms of physiology, urine samples were collected at 1200 hours at P 2 and $1 \times$ in each of weeks 2, 4, 8 and 12, for determination of basal cortisol relative to creatinine. A blood sample was also collected at week 12 for determination of plasma ACTH and cortisol (Hauser et al. 2007). Blood samples were also obtained at 1200 hours and $1 \times$ per week in weeks 20,24, 28, 32, 40, 44 and 48, for determination of plasma ACTH and cortisol (Hauser et al. 2008). In terms of behaviour, the aim was to investigate several emotional, cognitive and motor domains and to do so in a longitudinal manner. It is important to note that all behavioural observation and testing were conducted with the subjects in their home cages, thereby excluding any possibility that stress induced by exposure to social isolation in a novel environment could confound effects of prenatal DEX. Thus, at age postnatal weeks 1-12, 20$24,28-32,36-40$ and $48-52$, behaviour of subjects in their home cage and with their family group (mother, father, twin) was observed, for 1-3 h per week/group. At age 2224 weeks, the effects of prenatal DEX exposure on performance of a motor skilled reaching task was assessed. The apparatus and design were adapted from a rat and mouse paradigm (Hauser et al. 2008). Using a Wisconsin general test apparatus placed adjacent to the home cage, monkeys were able to reach through an opening in a transparent Plexiglas screen and retrieve a food reward from one of four indentations in a platform, located left/ right $\times$ near/far relative to the subject. Subjects were trained to perform the basic retrieval task and then were tested on 16 trials per day for four consecutive days. The scores of interest were single attempt success (subject obtains reward within the first time of reaching through the opening, regardless of any errors), and single grasp success (subject obtains reward within the first time of reaching through the opening, and without any errors) (Hauser et al. 2008). Beginning at age 40 weeks, using the monkey version of the Cambridge Neuropsychological Automated Test Battery (CANTAB), subjects were operantly trained to touch a stimulus on a touch sensitive screen in order to obtain palatable reward. When the subjects were trained on this basic task and were responding at a consistent and stable rate, they were tested on the following consecutive tests: progressive-ratio reinforcement schedule (44 weeks), fixedratio reinforcement schedule (48 weeks), and simple discrimination and reversal learning (56 weeks) (Hauser et al. 2008). The progressive-ratio task used a large, single stimulus, and at each trial, the subjects had to perform more responses to obtain reinforcement than on the previous trial. The measures were total number of responses (stimulus touches), total rewards obtained, and breakpoint ratio (number of responses required for next reward when subject stopped responding). On the fixed-ratio reinforcement task, subjects were given a fixed-ratio 10 (ten responses for each reward) schedule, using the same operant stimulus as for the progressive-ratio task. For simple discrimination and reversal, subjects were tested in two-way simple discrimination followed by reversal learning; the learning criterion was eight consecutive correct responses (Hauser et al. 2008).

There were no significant effects of Treatment on urinary cortisol/creatinine titres or plasma ACTH or cortisol titres ( $p>0.05$ ) (Hauser et al. 2007, 2008). In terms of behaviour, the significant effects of the prenatal DEX treatment that were observed in this longitudinal developmental study are presented in Table 1. With respect to home cage behaviour in infancy, there was a significant effect of EDEX on percent time in a mobile state, which was increased in EDEX infants relative to VEH and LDEX infants. Secondly, EDEX infants spent significantly more time eating solid food than did VEH and LDEX infants. As juveniles, EDEX subjects initiated social play with their sibling and parents significantly less frequently than did VEH and LDEX juveniles. On the skilled reaching task measures, there was a significant interaction between Treatment and Session, which was primarily attributable to an absence of improved performance across sessions in LDEX marmosets relative to VEH and EDEX. This was the case both for single attempt success and single grasp success. For single grasp success, it was also the case that EDEX exhibited a delay in improvement of performance across sessions relative to VEH subjects. On a fixed-ratio 10 schedule, there was a significant effect of Treatment on total number of responses and total number of rewards obtained: EDEX made more responses and obtained more rewards than did VEH and LDEX subjects.

The combination of significant effects of EDEX treatment on feeding motivation measures was striking, and could reflect prenatal DEX effects on the (food) reward network, given that central and peripheral components of appetite control/feeding motivation are under corticosteroid control (discussed in Hauser et al. 2007, 2008). With regard to the evidence for impairing effects of prenatal DEX on juvenile motor dexterity: the fine modulation of precise motor learning and performance, such as that required in 
Table 1 Summary of significant effects of prenatal dexamethasone exposure on behaviour

\begin{tabular}{|c|c|c|c|c|c|c|}
\hline Dependent variable & VEH & EDEX & LDEX & Comparison & $p$ & Reference \\
\hline \multicolumn{7}{|l|}{ Infancy (weeks 1-12) } \\
\hline$\%$ time spent mobile & $47 \pm 6$ & $56 \pm 6$ & $48 \pm 5$ & $\begin{array}{l}\text { EDEX }>\text { VEH } \\
\text { EDEX }>\text { LDEX }\end{array}$ & $\begin{array}{l}0.05 \\
0.05\end{array}$ & Hauser et al. (2007) \\
\hline$\%$ time eating solid food & $2 \pm 0$ & $2 \pm 1$ & $1 \pm 0$ & $\begin{array}{l}\text { EDEX }>\text { VEH } \\
\text { EDEX }>\text { LDEX }\end{array}$ & $\begin{array}{l}0.05 \\
0.05\end{array}$ & Hauser et al. (2007) \\
\hline \multicolumn{7}{|c|}{ Juvenilility-adolescence (weeks 20-48) } \\
\hline Initiate social play frequency/h & $6 \pm 1$ & $2 \pm 1$ & $5 \pm 1$ & $\begin{array}{l}\text { EDEX }<\text { VEH } \\
\text { EDEX }<\text { LDEX }\end{array}$ & $\begin{array}{l}0.05 \\
0.05\end{array}$ & Hauser et al. (2008) \\
\hline Skilled reaching task & & & & & & Hauser et al. (2008) \\
\hline$\%$ single attempt success & $78 \pm 3$ & $75 \pm 4$ & $63 \pm 4$ & Treatment $\times$ block & 0.001 & \\
\hline$\%$ single grasp success & $51 \pm 3$ & $30 \pm 4$ & $33 \pm 4$ & Treatment $\times$ block & 0.001 & \\
\hline \multicolumn{7}{|l|}{ Adolescence (week 48) } \\
\hline Fixed-ratio 10 reinforcement & & & & & & Hauser et al. (2008) \\
\hline Total responses & $190 \pm 9$ & $345 \pm 15$ & $206 \pm 11$ & $\mathrm{EDEX}>\mathrm{VEH}$ & 0.005 & \\
\hline Total reinforcements & $14 \pm 2$ & $33 \pm 4$ & $15 \pm 5$ & $\mathrm{EDEX}>\mathrm{VEH}$ & 0.005 & \\
\hline
\end{tabular}

Data are presented as mean \pm SEM

the skilled reaching task used in this study, has been demonstrated by lesion studies to be mediated by the cerebellum and the dependent cerebello-thalamo-cortical pathway, and by the basal ganglia and the dependent striato-thalamo-cortical loop. Prenatal glucocorticoid receptor activation, including via synthetic agonists, reduces neurogenesis and cellular connectivity in the cerebellum and alters striatal dopaminergic activity (discussed in Hauser et al. 2008). Importantly, each of these long-term behavioural effects of prenatal DEX exposure occurred in the absence of long-term effects on the HPA axis, at least as assessed via measurement of basal levels of ACTH and cortisol in urine and/or plasma samples.

In terms of neuroanatomy, in newborn marmosets that were exposed to either EDEX or LDEX, the dentate gyrus exhibited reduced proliferation of putative precursor cells but not reduced differentiation of mature cells, relative to VEH subjects (Tauber et al. 2006). Importantly, in their adult siblings the decreased proliferation rate was no longer detectable (Tauber et al. 2008). Also in newborns, LDEX subjects exhibited reduced glucocorticoid receptor (GR) mRNA levels in the medial, orbital and dorsal prefrontal cortex (PFC), and EDEX subjects exhibited reduced GR expression in the dorsal PFC. Moreover this latter treatment, specifically, resulted in significant reduction in the mRNA expression of calcyon, a risk gene for attentiondeficit/hyperactivity disorder (Heijtz et al. 2007), in the medial, orbital, dorsal and lateral PFC relative to controls. Again these prenatal DEX effects were not present at adulthood (Diaz Heijtz et al. 2010). Localised proton magnetic resonance spectroscopy (MRS) was performed to assess cerebral metabolite profiles (e.g. glutamate, glutamine, N-acetylaspartate) in vivo and to determine putative alterations of adult brain metabolism in EDEX and LDEX marmosets (Michaelis et al. 2009). In volumes-ofinterest that constituted gray matter above corpus callosum and white matter in the corpus callosum, there were no significant effects of DEX treatment on adult brain metabolism.

Developmental consequences of postnatal social stress for HPA function, behaviour and CNS in the common marmoset

In monkeys and apes, there is continuous physical contact between the mother and its single infant for several weeks after birth. The marmosets and tamarins represent an exception to this in that infants are typically twins, and these twins are in continuous physical contact with communal caregivers, i.e. the mother, father and older siblings, rather than with the mother exclusively. We conducted studies in which young infants were separated from their caregivers and placed in an isolation chamber on a daily basis, for between 30-120 min per day, on postnatal days (P) 2-28, a procedure we termed early deprivation (ED) (Dettling et al. 2002). The (1) exposure to an absence of caregiving, and (2) being alone in a novel environment, is an atypical ("unexpected") constellation of events for monkey infants. The ED manipulation was studied because it has parallels to parental neglect of human infants in extant families, which, as demonstrated by epidemiological studies, is associated with developmental psychopathology (Kendler et al. 2002). Second, marmoset ED has parallels to the common parenting practices in Western society of 
regular breaking of infant-parent contact e.g. placing the infant down to sleep (McKenna et al. 2007), enrolling the infant in daily child care, the latter often involving exposure of the infant to frequent changes in (i.e. novel) caregivers (Gunnar and Quevedo 2007; Gunnar 1992). Of course, in addition to its attributes as a model of human parent-infant neglect, the marmoset ED procedure has over-lapping characteristics with those manipulations used to study the effects of early life stress in rats. Rat litters have been exposed to daily periods of $15 \mathrm{~min}$ separation (early handling, EH) or 180-240 min separation (maternal separation, MS) (Levine 1994, 2002; Pryce and Feldon 2003). These manipulations are partly confounded by their impact on active maternal behaviour such as anogenital licking and arch-back nursing, which is increased by EH and MS in rat (Pryce et al. 2001). Nonetheless, a number of important long-term effects of MS have been demonstrated in rat, including increased stressor responsiveness in terms of circulating $\mathrm{ACTH}$ and corticosterone, reduced DEX suppression of circulating ACTH and corticosterone, decreased hippocampal glucocorticoid receptor expression, increased hippocampal mineralocorticoid receptor expression (Ladd et al. 2004; Plotsky and Meaney 1993a; Pryce and Feldon 2003).

As this was the first such study of repeated, daily separation of the infant-caregiver bond in a species of nonhuman primate, the manipulation had to be piloted for its feasibility: indirect evidence suggesting that the paradigm would be feasible was provided by the descriptions of successful human hand-rearing of common marmoset infants by rotation in cases of triplet births (Hearn and Burden 1979). The evidence we obtained was that infants survived ED and exhibited a moderate stress response to ED on each day of the manipulation, and that parents readily retrieved the infant at reunion, and that there was no effect on parental behaviour (Dettling et al. 2002). The control $(\mathrm{CON})$ procedure involved restraining the parent carrying the control infant(s), as for ED, and then briefly handling the infant on the parent (Dettling et al. 2002).

Before describing the effects of ED, it is important to explain the method of subject assignment to the ED and control manipulations across twin infants and births. Probably the obvious design would be to, within a twin pair, randomly allocate one twin to the ED treatment and one to the CON treatment. However, we were concerned that, using such a split-twin design, it would be possible for effects of ED on the behaviour of the ED twin to impact on the behaviour of the CON twin and thereby reduce the magnitude of any ED direct effect. Therefore, the design used in the first study was conservative, and involved exposing both twins to ED or both to CON and then, in a subsequent birth to the same breeding pair, exposing both twins to the other manipulation (Dettling et al. 2002). This matched ED twin-CON twin experimental design was conducted with ten breeding pairs of common marmosets, therefore yielding 40 study subjects as ten pairs of ED twins and 10 pairs of CON twins, and a manipulation $\times$ parentage full-interaction statistical model that allowed for analysis of treatment and parentage main effects and treatment-parentage interaction effects. Based on the findings of this study, which are summarised below, in subsequent studies, the original findings of which are reported on here, the experimental design was the splittwin design: In breeding pairs of common marmosets, with each twin pair, one twin was assigned at random to the ED treatment and the other twin to the CON treatment, consistent with a statistical model that allowed for analysis of treatment and parentage main effects but not their interaction. The rationale for this change in study design was that a number of consistent physiological and behavioural main effects of ED were obtained in the first study, and that the ED effect was considered robust enough for effects to pertain even in the presence of some dilution by between-twin effects of ED on the CON phenotype, or vice versa.

\section{Summary of the findings in the matched ED twins versus CON twins study}

The effects of ED on marmoset development were studied from age P 2 until postnatal week 48. On each day of ED ( $\mathrm{P}$ 2-28), urine samples were obtained immediately after removal of the ED infant from the carrying parent (pre-ED) and immediately after the ED session (post-ED) (Dettling et al. 2002). In these urine samples, cortisol titres were measured and expressed relative to creatinine (CR). In postnatal weeks $1-8,12-$ $15,35-36$, home cage behaviour was measured for $3 \mathrm{~h}$ per week per group. From week 9 on, a weekly first-void morning urine sample was collected in the home cage for determination of basal urinary cortisol. At age 20 weeks, subjects were tested in the home cage in terms of their ability to learn and perform an object retrieval/detour task: a palatable reward was placed inside a transparent plastic cube that was open on one side only. The solid sides of the cube were indicated with black lines to reduce the perceptual demands of the task (Pryce et al. 2004a). At age 30 weeks, using the monkey version of CANTAB, subjects were trained in the home cage and at age 36 weeks, were tested on a two-way visual discrimination task followed by reversal and re-reversal; at age 42 weeks, they were tested on a progressive-ratio schedule of reinforcement (Pryce et al. 2004b). Subjects were killed at 48 weeks, with the brain either fresh fixed or perfused fixed (Arabadzisz et al. 2010).

The statistical main effects of the ED treatment on physiological and behavioural measures that were observed are presented in Table 2. For the acute effect of ED on 
Table 2 Summary of significant main effects of early deprivation on in vivo measures obtained using a matched early deprivation twin-control twin experimental design

$C R$ creatinine, $E D$ early deprivation, $h$ hour, ORDT object reaching/detour task, $P M$ afternoon, $P 28$ postnatal day 28 Data are presented as mean \pm SEM

\begin{tabular}{|c|c|c|c|c|}
\hline Dependent variable & Early deprivation & Control & $p$ & Reference \\
\hline \multicolumn{5}{|l|}{ Infancy, pre- vs post-ED } \\
\hline Urinary cortisol/CR, PM $(\mu \mathrm{g} / \mathrm{mg})$ & $\begin{array}{l}\text { Pre-ED } 121 \pm 9 \\
\text { Post-ED } 183 \pm 17\end{array}$ & & 0.03 & Dettling et al. (2002) \\
\hline \multicolumn{5}{|l|}{ Infancy } \\
\hline Body weight at P 28 (g) & $56 \pm 2$ & $63 \pm 3$ & 0.003 & Dettling et al. (2002) \\
\hline Distress vocalization $/ \mathrm{h}$ & $3 \pm 1$ & $2 \pm 0$ & 0.05 & Dettling et al. (2002) \\
\hline \multicolumn{5}{|l|}{ Juvenility } \\
\hline ORDT test, impulsive errors & $5 \pm 1$ & $2 \pm 1$ & 0.03 & Pryce et al. (2004b) \\
\hline \multicolumn{5}{|l|}{ Adolescence } \\
\hline Reversal learning errors & $177 \pm 26$ & $126 \pm 9$ & 0.04 & Pryce et al. (2004a) \\
\hline Re-reversal learning errors & $225 \pm 24$ & $127 \pm 8$ & 0.002 & Pryce et al. (2004a) \\
\hline \multicolumn{5}{|l|}{ Progressive ratio } \\
\hline Reinforcements & $9 \pm 2$ & $12 \pm 1$ & 0.04 & Pryce et al. (2004a) \\
\hline Time of last response (s) & $548 \pm 80$ & $704 \pm 55$ & 0.02 & Pryce et al. (2004a) \\
\hline
\end{tabular}

urinary cortisol titres, there was a significant increase when ED was carried out in the afternoon (Dettling et al. 2002). Home cage social behaviour of infants and parents at subject age 1-8 weeks was largely unaffected by ED, although ED infants did exhibit an increased frequency of emitting distress vocalizations (Dettling et al. 2002). The object retrieval/detour task provides a measure of impulsivity in terms of trials where subjects fail to inhibit an attempt to retrieve the reward from within the transparent plastic cube by reaching forwards rather than retrieving via the opening to the side of the cube. The ED subjects committed significantly more impulsive responses in session 2 of the four 16-trial sessions than did CON subjects (Pryce et al. 2004a). Using home cage CANTAB, ED adolescents exhibited a significant deficit in reversal learning and re-reversal learning relative to CON subjects. On a progressive-ratio schedule, ED adolescents exhibited reduced responding and ceased responding earlier, thereby receiving fewer reinforcements, relative to CON adolescents (Pryce et al. 2004b).

In terms of ex vivo neuroanatomy (Table 3), ED adolescents exhibited significantly decreased expression of the genes for the glucocorticoid receptor (GR) and mineralocorticoid receptor (MR) in the hippocampus specifically, as measured using in situ hybridization

Table 3 Summary of significant main effects of early deprivation on ex vivo measures of neurobiological parameters using a matched early deprivation twin-control twin pair experimental design

\begin{tabular}{|c|c|c|c|c|}
\hline Dependent variable & Early deprivation & Control & $p$ & Reference \\
\hline \multicolumn{5}{|l|}{ Hippocampus: mRNA } \\
\hline GR: DG, CA1-4 (kBq/g) & $5 \pm 0$ & $6 \pm 0$ & 0.02 & Arabadzisz et al. (2010) \\
\hline MR: DG, CA1-4 (kBq/g) & $20 \pm 1$ & $22 \pm 1$ & 0.05 & Arabadzisz et al. (2010) \\
\hline GAP-43: DG (nCi/g) & $79 \pm 5$ & $103 \pm 9$ & 0.05 & Law et al. (2009a) \\
\hline GAP-43: CA3 (nCi/g) & $105 \pm 11$ & $141 \pm 12$ & 0.03 & Law et al. (2009a) \\
\hline VGAT: CA3 (nCi/g) & $148 \pm 8$ & $105 \pm 5$ & 0.007 & Law et al. (2009a) \\
\hline 5-HT ${ }_{1 \mathrm{~A}} \mathrm{R}: \mathrm{CA} 1(\mathrm{nCi} / \mathrm{g})$ & $83 \pm 3$ & $101 \pm 6$ & 0.05 & Law et al. (2009a) \\
\hline \multicolumn{5}{|l|}{ Hippocampus: binding } \\
\hline 5-HT ${ }_{1 \mathrm{~A}} \mathrm{R}: \mathrm{CA} 1$ (nCi/g) & $76 \pm 4$ & $85 \pm 4$ & 0.05 & Law et al. (2009a) \\
\hline \multicolumn{5}{|l|}{ Anterior cingulated cortex: mRNA } \\
\hline Spinophilin: subgenual ACC (nCi/g) & $118 \pm 3$ & $175 \pm 8$ & 0.02 & Law et al. (2009b) \\
\hline \multicolumn{5}{|l|}{ Anterior cingulated cortex: binding } \\
\hline 5-HT ${ }_{1 \mathrm{~A}} \mathrm{R}$ : superficial subgenual ACC (nCi/g) & $14 \pm 1$ & $10 \pm 1$ & 0.02 & Law et al. (2009b) \\
\hline 5-HT ${ }_{1 \mathrm{~A}} \mathrm{R}$ : deepl subgenual ACC (nCi/g) & $15 \pm 2$ & $20 \pm 2$ & 0.04 & Law et al. (2009b) \\
\hline
\end{tabular}

Results are presented as mean $\pm \mathrm{SEM}$

$A C C$ anterior cingulated cortex, $C A 1-4$ cornu amonis subregions $1-4, D G$ dentate gyrus, GAP-43 growth-associated protein-43, $G R$ glucocorticoid receptor, $M R$ mineralcorticoid receptor, $V G A T$ vesicular GABA transporter, $5-H T_{I A} R$ serotonin $1 \mathrm{~A}$ receptor 
(Arabadzisz et al. 2010). Also in the hippocampus, ED adolescents exhibited significantly decreased gene expression of growth-associated protein-43 (GAP-43) and significantly increased expression of the vesicular GABA transporter (Law et al. 2009b). Gene expression and receptor binding of the serotonin $1 \mathrm{~A}$ receptor $\left(5 \mathrm{HT}_{1 \mathrm{~A}} \mathrm{R}\right)$ were significantly decreased in ED versus CON adolescents in the hippocampus and deep laminae of the subgenual anterior cingulate cortex (ACC) and $5 \mathrm{HT}_{1 \mathrm{~A}} \mathrm{R}$ binding was significantly increased in the superficial laminae of subgenual ACC (Law et al. 2009a, b). Expression of the gene for the postsynaptic protein spinophilin was significantly decreased in the subgenual ACC (Law et al. 2009a).

\section{Studies of the effects of ED using the split-twin design}

Based on the evidence for robust main effects of ED on some of the targeted parameters in the matched ED twin-CON twin study, we proceeded with studies using the split-twin, EDCON design. The aims of a first such study (study I) were to investigate the effects of ED on basal and stress levels of cortisol in the circulation, and on home cage behaviour, in infancy. The aims of a second study (study II) were to investigate the effects of ED on basal and stress-challenge levels of cortisol in the circulation in juveniles and adolescents. The aims of a third study (study III) were to investigate the effects of ED on EEG/sleep macroarchitecture in juveniles.

\section{Study I}

This study was conducted with six pairs of twins (three male-male pairs, two female-female pairs and one male- female pair) born to different breeding pairs. The same ED manipulation was performed as in the ED-CON twin study, but blood samples rather than urine samples were obtained. In ED infants, basal blood samples were collected immediately prior to ED at 1100 hours on P 7, 14, and 28, and stress-response blood samples were collected after 30min ED on P 7 and 28. In CON infants, basal blood samples were collected at 1100 hours on P 14 and 28. The circulating cortisol response to social separationnovelty (SSN) challenge was studied at postnatal week 8. In most cases, basal and SSN blood samples were collected within 2 min of entering the home cage, and the delay never exceeded $5 \mathrm{~min}$. In postnatal weeks 1-9, home cage behaviour was measured for $3 \mathrm{~h} /$ group/week. Further details to study I are reported in (Maier 2003).

Plasma cortisol titres of ED infants immediately pre- and post-ED are given in Fig. 3a: there was no significant effect involving Condition $(p>0.05)$. There was a significant main effect of Age $(F(1,4)=9.40, p=0.04)$ with infants exhibiting lower cortisol titres at week 4 than at week 1. In terms of basal plasma cortisol titres in ED and CON infants (Fig. 3b), there was a significant main effect of manipulation $(F(1,4)=17.51, p=0.01)$ with cortisol titres higher in ED animals, and of parentage $(F(5,4)=11.52, p=0.02)$. There was also a significant main effect of age $(F(2,8)=$ $11.12, p=0.005)$ due to the decrease in cortisol titres with age. In the SSN challenge test at week 8 , there was no significant effect involving manipulation on plasma cortisol titres (Fig. 4). There was a significant main effect of parentage $(F(5,4)=13.25, p=0.01)$ and of time $(F(2,8)=$ $56.79, p=0.001$ ) with both $30 \mathrm{~min}$ and $120 \mathrm{~min}$ samples

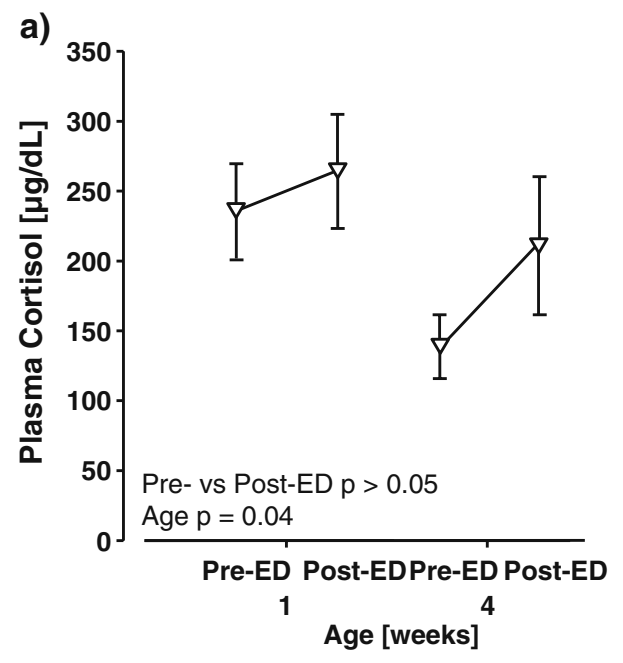

Fig. 3 Effects of early deprivation on plasma cortisol titres in infancy. a Plasma cortisol titres in ED common marmosets $(N=6)$ in samples obtained immediately after removal of the infant from the carrying parent (Pre-ED, 1100 hours) and immediately after a 30-min ED session (Post-ED, 1130 hours). There was not a significant effect of

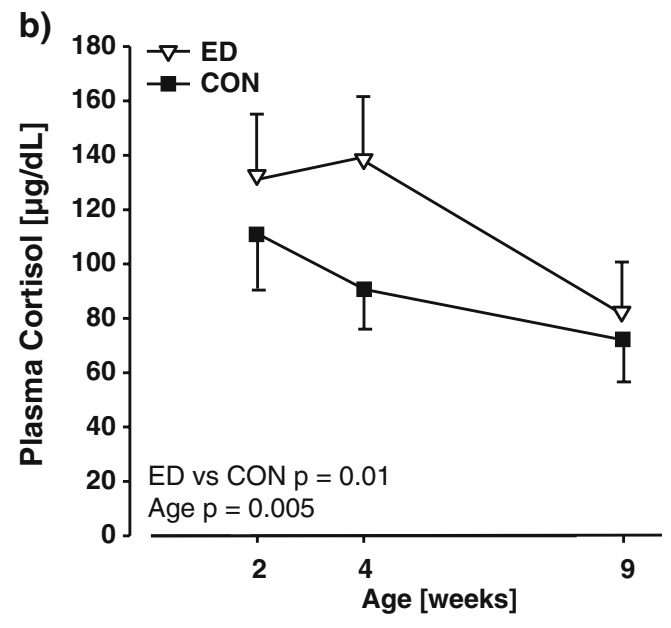

condition on plasma cortisol titres. b. Comparison of plasma cortisol titres in ED and CON infant common marmoset twins $(N=6,6)$ in samples obtained immediately after removal of the infant from the carrying parent (1100 hours). Titres were significantly greater in ED versus $C O N$ infants. Values are mean \pm SEM 


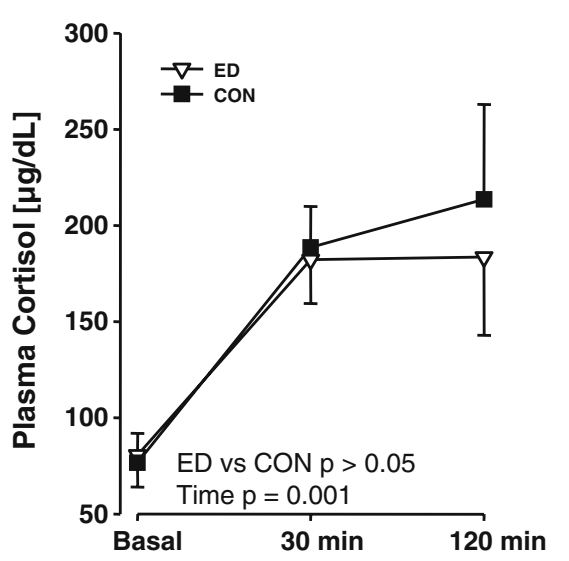

Fig. 4 Comparison of effects of social separation on plasma cortisol titres in juvenile ED and CON common marmoset twins $(N=6,6)$. Values are mean \pm SEM. There was not a significant effect of Manipulation on plasma cortisol titres

exhibiting similarly increased cortisol titres compared with the basal sample.

In terms of home cage behaviours (Fig. 5), for anogenital licking of the infant by the mother (Fig. 5a), there was a significant manipulation $\times$ age interaction $(F(2,6)=5.74, p=$ $0.04)$ and a significant main effect of manipulation $(F(1,3)=$ 23.74, $p=0.02)$ : post hoc analysis revealed that with infants aged 1-4 weeks, mothers performed more anogenital licking with CON than ED infants. For per cent time spent being carried by parents (Fig. 5b), there was a significant manipulation $\times$ age interaction $(F(2,6)=7.35, p=0.02)$ and a significant main effect of manipulation $(F(1,3)=11.62, p=$ 0.04): post hoc analysis revealed that ED infants aged 58 weeks were carried significantly more than were their CON siblings. At weeks 5-8 and 9, play behaviour was observed in the form of both solitary and social play. There was not a significant effect of treatment on the amount of time spent in either social or solitary play/exploration. However, in terms of attempts made to initiate social play (Fig. $5 \mathrm{c}$ ), there was a significant manipulation $\times$ age interac- tion $(F(1.3)=13.25, p=0.04)$ and a significant manipulation main effect $(F(1,3)=48.02, p=0.006)$ : post hoc analysis revealed that at age 9 weeks, CON infants made significantly more attempts to initiate social play than did their ED siblings.

The lack of a significant stress response to 30-min ED (pre- versus post-ED) in terms of plasma cortisol titres in infants aged 1 and 4 weeks is an important addition to our understanding of the acute effects of ED in infant marmosets. Basal titres of circulating and cerebrospinal fluid cortisol are higher in infancy, particularly in week 1, than at any subsequent life stage in common marmoset (Pryce et al. 2002), and it is therefore possible that there is a "floor effect" on the ability of the infant marmoset to exhibit a HPA axis stress response, including to ED. The time point used for the current study was mid-day. As described above, in the matched ED twin-CON twin study, there was an acute increase in urinary cortisol following ED, but only when the ED procedure was carried out in the afternoon when, in infants older than 1 week, basal plasma cortisol titres are at a circadian nadir (Dettling et al. 2002; Pryce et al. 2002). It is therefore possible that plasma and urinary cortisol are not optimal markers of the acute stress effects of ED. Indeed, in the matched ED twin-CON twin study, urinary catecholamines were more responsive to ED than was cortisol (Dettling et al. 2002). Of course, if there was an effect of daily ED in terms of increased basal cortisol titres, this would further increase any floor effect in the infant marmoset's ability to exhibit a cortisol stress response. And indeed, the present study demonstrated increased mid-day basal cortisol titres in ED versus CON marmosets at weeks 2 and 4 (Fig. 3b). The increase in basal cortisol in ED infants relative to their CON siblings was most marked at week 4, and basal cortisol titres were similar in ED and CON infants by age 9 weeks.

In terms of behavioural effects, mothers performed anogenital licking episodes with the CON infant about
Fig. 5 Comparison of social behaviours that were significantly different in ED and CON infant common marmoset twins $(N=6,6)$ : a Frequency of maternal anogenital licking of infants aged 1-4 weeks. b Percent time being carried by parents in infants aged 5-8 weeks. c Frequency of initiating an episode of social play by infants aged 9 weeks. Values are mean \pm SEM

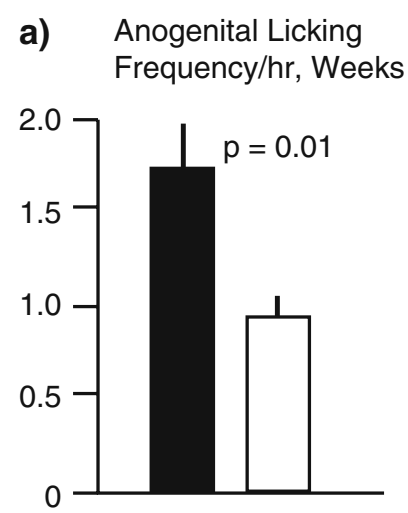

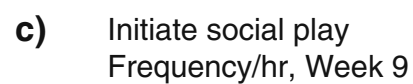
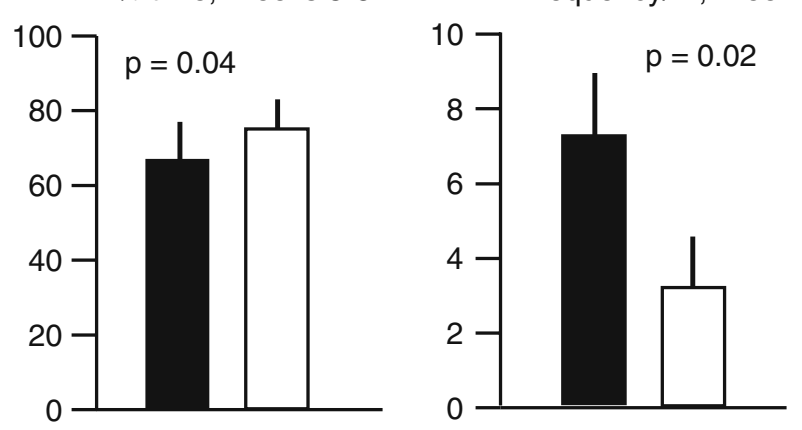

$\operatorname{CON}(\mathrm{N}=6)$ 
twice as often as with the ED infant, during weeks 1-4. Although this was not the case in the ED twin-CON twin study (Dettling et al. 2002), the present finding is certainly of importance in the context of rodent studies: Anogenital licking of the infant by the parent is important to stimulate urination and defecation. In rats, postnatal manipulations including EH and MS have been demonstrated to induce increased levels of anogenital licking. There are also marked spontaneous differences between dams in the amount of anogenital licking behaviour they perform. There is evidence from both experimental and correlational studies that adult offspring that received high levels of anogenital licking as pups exhibit reduced HPA axis stress reactivity and reduced levels of anxious behaviour (Suchecki et al. 1993; Weaver et al. 2004). Extrapolating these rodent data to the marmoset, it is possible that the reduced anogenital licking experienced by ED infants contributed to the ED effects observed. The finding that ED infants aged 5-8 weeks spent more time being carried by the mother could indicate that their physical development was mildly delayed and/or that their motivation to be carried was increased, relative to CON. That ED infants were less likely to initiate social play with their twin or parents than were their CON siblings was not observed in the ED twin-CON twin study (Dettling et al. 2002).

\section{Study II}

This study was conducted with ten pairs of twins (three male-male pairs, three female-female pairs and four malefemale pairs) born to 10 different breeding pairs. The ED manipulation was conducted as in the matched ED twinCON twin study. Basal blood samples were obtained from ED and CON subjects in weeks 28, 40 and 50: two samples were obtained per time period, one at 0800 and one at 1900 hours, with an interval of 1 week. At age 20 weeks, subjects were exposed to a social stressor in the form of social isolation of the twins in the home cage i.e. removal of the parents, for analysis of plasma cortisol responses. At age 42 weeks, subjects were exposed to a physical stressor in the form of a subcutaneous saline injection: At 1200 hours, one of the twins was blood sampled (Basal), and then immediately injected s.c. with $0.9 \%$ saline solution at $1 \mathrm{ml} / \mathrm{kg}$ and returned to its home cage. Subsequent blood samples were collected after 60, 120 and $240 \mathrm{~min}$. At age 44 weeks, subjects were exposed to a dexamethasone/CRH neuroendocrine challenge: The aim of this experiment was to investigate the effects of ED on GRmediated suppression of HPA axis function by DEX, both per se and following exogenous CRH challenge. The test design was based largely on the DEX/CRH challenge test developed for use as a method with which to demonstrate altered HPA function in depression (Heuser et al. 1994), which has also been applied in rat (Buwalda et al. 1999). The dose of DEX selected, $1 \mathrm{mg} / \mathrm{kg}$, was based on a previous dose-response study of DEX effects on HPA function in adult common marmoset (Saltzman et al. 2004), and the dose of $\mathrm{CRH}$ selected, $5.0 \mu \mathrm{g} / \mathrm{kg}$, was based on a previous study of CRH effects on HPA function in adult common marmoset (Johnson et al. 1996). On test day 1, at 1900 hours, the subject was injected i.m. with $0.9 \%$ saline solution at $0.5 \mathrm{ml} / \mathrm{kg}$ into the hind leg. On test day 2 , at 0800 hours, a blood sample (SAL AM) was taken, and at 1900 hours, $1.0 \mathrm{mg}$ DEX/0.5 ml SAL/kg (dexamethasone phosphate) was injected i.m into the hind leg. On test day 3 , at 0800 hours, a blood sample (DEX AM) was taken. At 1400 hours, a blood sample was taken (Pre-CRH). The subject was then anaesthetized using isoflourane (3\%), and $5.0 \mu \mathrm{g} \mathrm{oCRH} / \mathrm{kg}$ body weight was injected into the femoral vein, using the opposite leg to that used for blood sampling. Anaesthesia was terminated and the subject returned to its home cage at 1405-1410 hours. Further blood samples were collected 60 and 180 min after oCRH injection (CRH response 1 and $3 \mathrm{~h}$ ). Blood plasma ACTH and cortisol levels were measured (Pryce et al. 2002).

For daily urinary cortisol responses of ED infants to ED (Fig. 6), there was a significant main effect of Condition ( $F$ $(1,7)=26.15, p=0.001)$, with post-ED cortisol titres being elevated compared with pre-ED titres. There was a significant interaction of age $\times$ time of day $(F(1,7)=5.64$, $p=0.05$ ): while there was almost no circadian change in cortisol titres in weeks $1+2$, PM cortisol titres were lower than AM cortisol titres in weeks 3+4. Basal plasma titres of cortisol were analysed using between subject factors of manipulation, parentage and sex, and repeated measure factors of age (weeks 28, 40, 50) and time of day (AM, PM). There was no significant effect involving manipulation

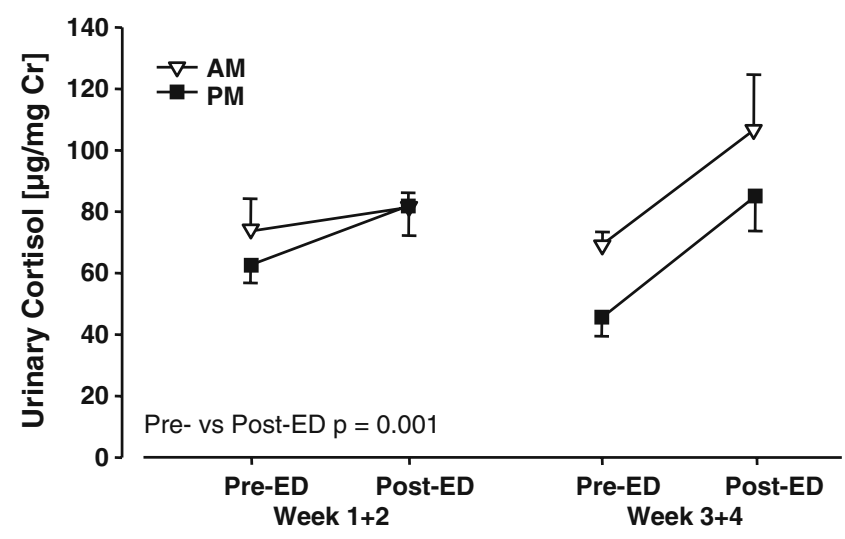

Fig. 6 Cortisol titres in ED common marmosets $(N=9)$ in urine samples obtained immediately after removal of the infant from the carrying parent (Pre-ED) and immediately after an ED session. Titres were significantly greater in post-versus pre-ED urine samples. Values are mean \pm SEM, with cortisol expressed relative to creatinine titres 


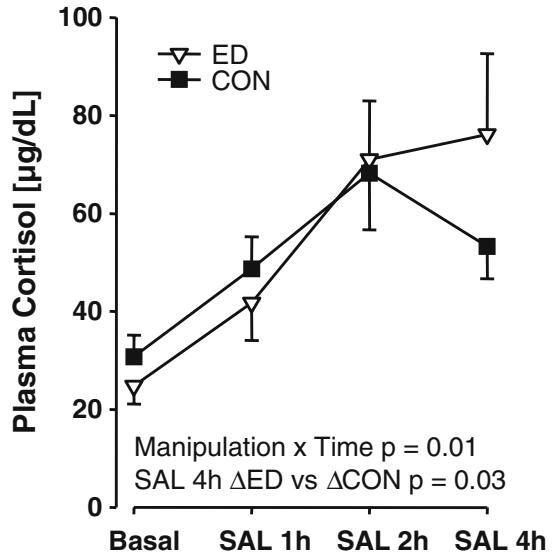

Fig. 7 Comparison of effects of saline injection (physical) challenge on plasma cortisol titres in adolescent $\mathrm{ED}$ and $\mathrm{CON}$ common marmoset twins $(N=7,7)$. Values are mean \pm SEM. There was a significant manipulation $\times$ time interaction. The $\Delta($ SAL $4 \mathrm{~h}-$ Basal) was significantly greater in ED versus $\mathrm{CON}$ juveniles on plasma cortisol titres. Values are mean $\pm \mathrm{SEM}$

(ED: $39 \pm 5 \mu \mathrm{g} / \mathrm{dL} ; \mathrm{CON}: 41 \pm 5 \mu \mathrm{g} / \mathrm{dL}$, mean $\pm \mathrm{SEM}$ ). There was a significant main effect of Time of day $(F(1,7)=605.32$, $p<0.001$ : AM: $71 \pm 3 \mu \mathrm{g} / \mathrm{dL}$; PM: $9 \pm 1 \mu \mathrm{g} / \mathrm{dL})$.

In the social separation challenge, there was a significant main effect of Time $(F(2,10)=27.49, p<0.001)$ with plasma cortisol titres increased at 60 and 120 min relative to basal and increased at $120 \mathrm{~min}$ relative to $60 \mathrm{~min}$. There was no significant effect involving manipulation. In the saline injection challenge (Fig. 7), there was a significant interaction of manipulation $\times$ time $(F(3,12)=5.51, p=0.01)$ and a significant main effect of time $(F(3,12)=31.79, p=$ $0.001)$ on plasma cortisol titres: a posteriori comparison of ED and CON in terms of cortisol titres at $4 \mathrm{~h}$ post-injection using a paired $t$ test did not yield a significant effect. When the delta of each subject's 4-h value relative to its basal value was used, ED subjects demonstrated a significant increase relative to $\mathrm{CON}(\Delta \mathrm{ED}: 51 \pm 14 \mu \mathrm{g} / \mathrm{dL}, \Delta \mathrm{CON}$ : $23 \pm 3 \mu \mathrm{g} / \mathrm{dL} ; t(5)=2.95, p=0.03)$.
In the combined DEX/CRH neuroendocrine challenge, for plasma ACTH titres (Fig. 8a), there was a significant manipulation $\times$ sample interaction $(F(4,16)=4.62, p=0.01)$ and a significant main effect of manipulation $(F(1,4)=$ $14.80, p=0.02$ ), and a significant main effect of parentage $(F(5,4)=24.93, p=0.004)$; there was a significant main effect of $\operatorname{sex}(F(1,4)=11.04, p=0.03)$, with males exhibiting higher ACTH titres than females; there was a significant main effect of sample $(F(4,16)=73.17, p<$ $0.001)$ mainly attributable to elevated ACTH levels at postCRH 1 h. A posteriori comparisons of ED and CON in terms of ACTH titres at the time points SAL AM and CRH $3 \mathrm{~h}$ using paired $t$ tests were not significant. When the delta of each subject's values at these time points relative to its basal value was used, there was a trend effect to an increased delta in ED versus CON subjects at SAL AM $(t$ $(5)=2.103, p=0.09)$ and CRH $3 \mathrm{~h}(\mathrm{t}(5)=-2.410, p=0.06)$. For plasma cortisol titres (Fig. 8b), there was a significant interaction of manipulation $\times$ sample $(F(4,16)=3.88, p=$ $0.02)$. There was a significant main effect of Sample $(F(4$, $16)=19.51, p<0.001)$ mainly attributable to low levels of cortisol at the DEX AM and Pre-CRH time points. $A$ posteriori comparison of ED and CON subjects at SAL AM and $\mathrm{CRH} 3 \mathrm{~h}$ did not yield statistical significance and this was also the case using delta values relative to basal titres.

The finding that ED resulted in acute increases in urinary cortisol titres, and in both AM and PM samples, represents the most robust evidence to-date that cortisol does increase in response to the daily ED manipulation. That the increase was significant, in contrast to that observed in plasma (see above), is probably at least in part attributable to the post-ED urine samples containing the cumulative cortisol released into the circulation and excreted during the 60-120 $\mathrm{min}$ ED; in contrast, blood samples were collected after 30-min ED. The lack of a chronic effect of ED on basal AM-PM plasma cortisol titres, as measured in blood samples obtained from juveniles and adolescents, concurs with the finding in the matched ED twin-CON study in which there was no effect
Fig. 8 Comparison of the effects of saline injection and DEX/CRH neuroendocrine challenge on a plasma ACTH and $\mathbf{b}$ plasma cortisol titres, in adolescent $\mathrm{ED}$ and $\mathrm{CON}$ common marmoset twins $(N=6,6)$. Values are mean \pm SEM. For $\mathrm{ACTH}$, there was a significant manipulation $\times$ sample interaction and a significant main effect of manipulation, with titres increased in ED versus CON subjects. For cortisol, there was a significant manipulation $\times$ sample interaction
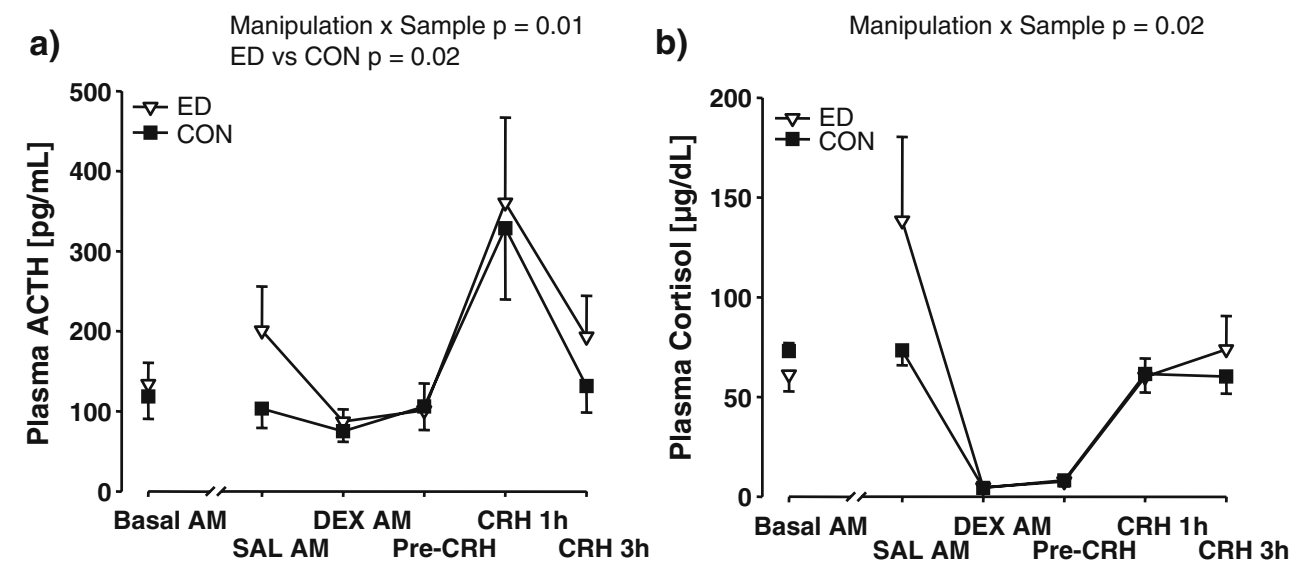
on basal first morning void urinary cortisol titres across the same age period (Dettling et al. 2007). In the physical challenge test (saline injection) in adolescent subjects, the evidence for a more prolonged plasma cortisol stress response in ED relative to $\mathrm{CON}$ adolescents suggests that post-stressor negative feedback within the CNS-HPA system is chronically impaired following ED. In the ex vivo matched $\mathrm{ED}$ twin-CON twin study, using in situ hybridization with marmoset-specific riboprobes, there was reduced $\mathrm{MR}$ and GR expression in the ED adolescent subjects in the hippocampus specifically (Arabadzisz et al. 2010; see Table 3). Accordingly, both a reduced proactive inhibition of the HPA response due to reduced hippocampal MR or a reduced reactive inhibition of the HPA response due to reduced hippocampal GR, or both processes, could contribute to this ED effect (De Kloet et al. 1998). Turning to the DEX/CRH neuroendocrine challenge test, to the best of our knowledge this is the first report of this test being applied in a monkey species. In order to assess the physical stress effects of a DEX injection at 1900 hours, we included a 1900 hours saline injection, and the most marked EDCON difference observed, in the case of ACTH and cortisol plasma titres, was at the following morning, 0800 hours time point (SAL AM, Fig. 7). This, in line with the more prolonged cortisol response observed in ED relative to CON adolescent subjects after the physical challenge (saline injection), suggests a more prolonged stress response/impaired negative feedback recovery in ED marmosets. That the interval between injection and sampling was greater than $12 \mathrm{~h}$ renders this effect particularly striking and unprecedented in our studies. One unusual feature of this experimental design was that the i.m. SAL injection was administered at 1900 hours, so that the findings might indicate an increase in stress reactivity of the HPA system during the basal nadir of HPA activity. The significant increase in plasma ACTH titres in ED relative to CON subjects was primarily attributable to the time points SAL AM and CRH $3 \mathrm{~h}$. At sample points DEX AM and Pre-CRH, ACTH titres were low in ED and CON subjects, and both groups exhibited a marked ACTH response to $\mathrm{CRH}$. The relatively high plasma ACTH titres in ED relative to $\mathrm{CON}$ at $\mathrm{CRH} 3 \mathrm{~h}$ suggests a relative reduction in DEX suppression of responsiveness to $\mathrm{CRH}$ challenge in ED subjects. The effect is not marked, but is perhaps comparable to that exhibited by DEX suppressor depression patients relative to controls in the human DEX/CRH test (Heuser et al. 1994). Such a reduced sensitivity to DEX effects on ACTH titres suggests reduced hypothalamic and/ or pituitary expression of GR in $\mathrm{ED}$ relative to $\mathrm{CON}$ adolescent marmosets. Our in situ hybridisation study indicated that there was no ED-CON difference in hypothalamic GR expression (Arabadzisz et al. 2010) and pituitary GR expression was not determined. It is notewor- thy that the CRH-stimulated increase in plasma $\mathrm{ACTH}$ titres was not matched by an equivalent increase in plasma cortisol, suggesting an extra-hypophyseal suppression of cortisol synthesis/release of the DEX dose used in addition to that mediated by reduced ACTH synthesis/release.

\section{Study III}

In this study, we investigated the effects of ED on sleep macroarchitecure in the common marmoset. In various mental illnesses and particularly in depression, sleep disturbance has long been recognised as a common complaint and has played a major role in the core symptomatology (DSM-IV 1994). Consistent findings from studies of the sleep macroarchitecture of depression include reduced latency to rapid eye movement (REM) sleep, decreased slow-wave sleep, and reduced sleep efficiency. The aim of this exploratory study was to investigate whether ED elicited changes in sleep patterns in juvenile common marmosets similar to alterations found in the clinical disorder.

In three family groups, each containing one ED and one CON twin (one male-male pair, two female-female pairs), sleep data were collected in the home cage by measuring electrical activity both in the cerebral cortex (electrocorticography, ECoG) and neck skeletal musculature (electromyography, EMG), and by continuous video recording of behaviour/ activity throughout the night. At the age of 15-18 weeks, each subject was surgically implanted with a two-channel biopotential radiotelemetry transmitter (weight $3.9 \mathrm{~g}$, volume $1.9 \mathrm{~cm}^{3}$; Data Sciences International, St Paul, MN, USA) (Pearce et al. 1997). Subjects' long-term recovery was assessed by comparing post-surgical social behaviour with pre-surgical behavioural baseline. Nocturnal ECoG and EMG data were transmitted by radiotelemetry and detected by a receiver positioned below the sleeping box. Sleep data of the ECoG/EMG system were recorded by Dataquest (Data Sciences International) and analysed with a dedicated sleep staging software (Somnologica, Flaga hf. Medical Devices, Reykjavík, Iceland). Recording of ECoG and EMG data was performed four times per subject, twice each at ages 17-22 and 22-26 weeks. Further details to this study are reported in (Aubert 2004).

Subjects' behaviour, e.g. time spent mobile and time spent in social play, had recovered to pre-surgery levels by the 2nd-3rd week after surgery. Examples of the EcoG signals that defined specific sleep stages are given in Fig. 9. Sleep was scored according to the rules developed by Rechtschaffen and Kales (Rechtschaffen and Kales 1968) for the scoring of sleep in humans, with minor modifications. The ECoG stages identified were awake, rapid eye movement (REM) sleep, light sleep (stages 1 and 2), and slow-wave sleep (SWS) (stages 3 and 4). 
Fig. 9 Nocturnal electrocorticographic (upper trace) and electromyographic (lower trace) signals characteristic of two different sleep stages as measured in freely moving juvenile common marmosets. a ECoG and EMG traces interpreted as typical for slow-wave sleep (stage 4) b ECoG and EMG traces interpreted as typical for rapid eye movement sleep

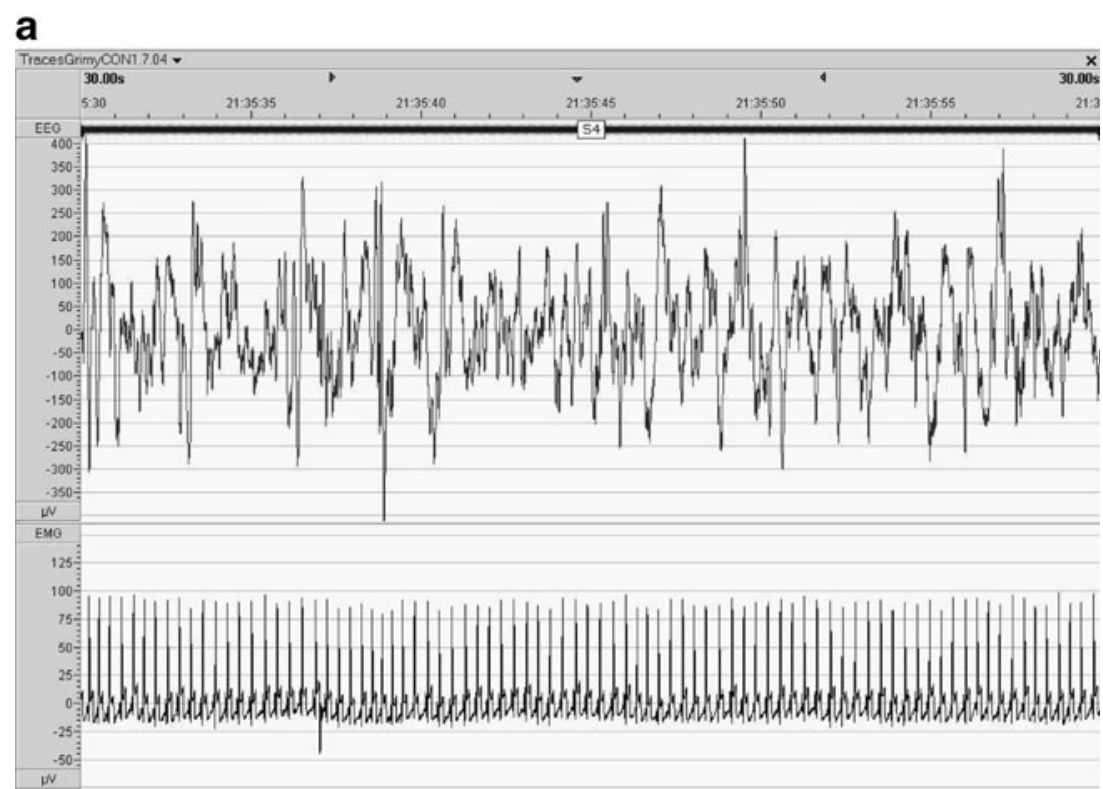

b

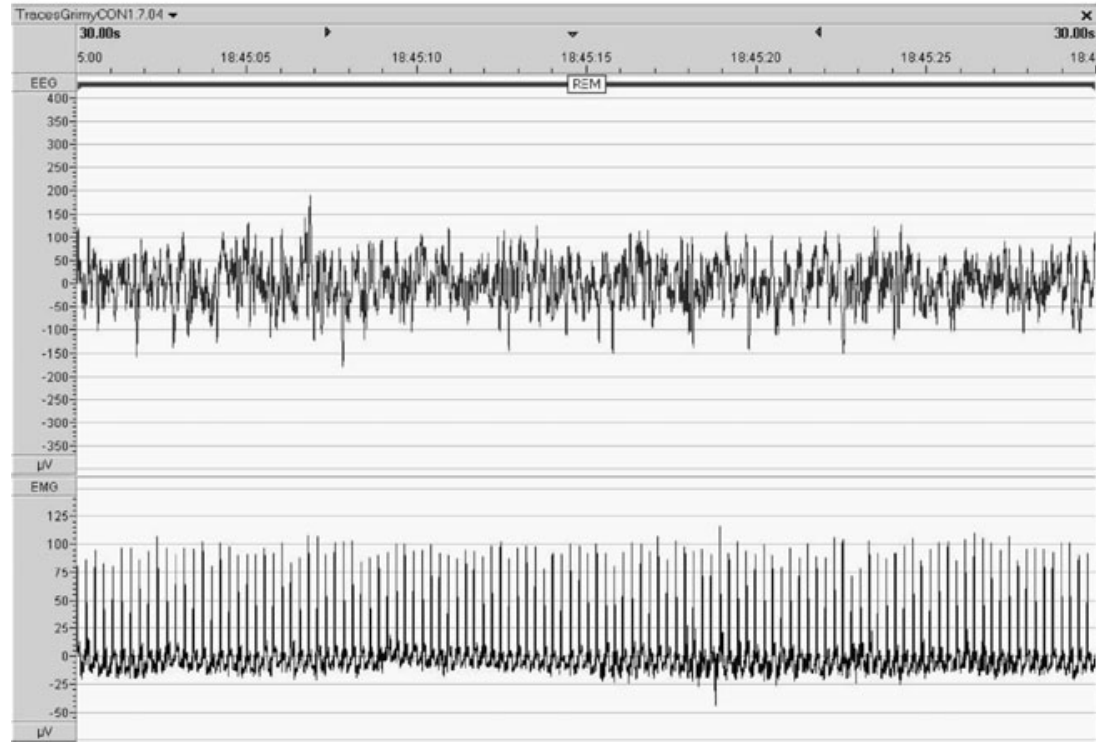

Table 4 lists the data obtained for the major sleep parameters measured, for both manipulation groups and two age blocks. There was no significant effect of manipulation or age on sleep efficiency, amount of REM sleep, amount of light sleep (S2), amount of SWS (S4), or total number of sleep stage transitions per hour of sleep. There was a significant main effect of manipulation on number of sleep stage transitions per hour, specifically from SWS to awake state $(F(1,4)=13.72, p=0.03)$, with ED animals performing more SWS to awake transitions than CON. The ED subjects exhibited a significantly higher total number of awakenings per hour than did CON $(F(1,4)=$ $7.72, p=0.05)$, although this difference was not seen when analysis was restricted to awakenings lasting longer than $60 \mathrm{~s}$. The ED subjects exhibited a significantly shorter SWS latency than did $\operatorname{CON}(F(1,4)=12.11, p=0.05)$. The REM sleep latency, reduction in which is one of the most robust sleep markers in adult depression, was not significantly different between ED and CON marmosets. There was a significant effect of Age on REM sleep latency and number of REM periods $(F(1,4)=7.879, p=0.05)$, with subjects exhibiting a shorter REM latency and an increased number of REM periods at age 17-22 weeks versus 22-26 weeks.

This exploratory study of the effects of ED on sleep macroarchitecture in juvenile common marmosets demonstrated an increase in the number of awakenings in ED relative to $\mathrm{CON}$ subjects. This could represent an analogue of decreased sleep continuity, a measure that is often observed in sleep-EEG in depression (Benca et al. 1992; Kupfer 1995; Nofinzger et al. 1999). The decrease in SWS 
Table 4 Summary of parameters describing sleep macroarchitecture in early deprived (ED; $n=3)$ and control $(\mathrm{CON} ; n=3)$ marmoset monkeys

\begin{tabular}{|c|c|c|c|c|c|}
\hline & \multicolumn{2}{|l|}{ ED } & \multicolumn{2}{|l|}{$\mathrm{CON}$} & \multirow[t]{2}{*}{$P$} \\
\hline & 17-22weeks & 22-26weeks & 17-22weeks & 22-26weeks & \\
\hline Sleep efficiency $(\%)$ & $70 \pm 1$ & $68 \pm 4$ & $65 \pm 4$ & $75 \pm 3$ & \\
\hline REM sleep (\%) & $26 \pm 1$ & $26 \pm 1$ & $24 \pm 1$ & $24 \pm 1$ & \\
\hline Light sleep (\%) & $54 \pm 2$ & $53 \pm 2$ & $55 \pm 2$ & $53 \pm 2$ & \\
\hline Slow-wave sleep (\%) & $17 \pm 2$ & $20 \pm 2$ & $17 \pm 1$ & $18 \pm 2$ & \\
\hline SST, total (f/h) & $18 \pm 1$ & $19 \pm 2$ & $15 \pm 1$ & $18 \pm 1$ & \\
\hline SST from SWS to awake (f/h) & $9 \pm 1$ & $12 \pm 1$ & $5 \pm 1$ & $5 \pm 1$ & $\mathrm{~T}:<0.03 \mathrm{ED}>\mathrm{CON}$ \\
\hline Awakenings, total (f/h) & $10 \pm 0$ & $10 \pm 0$ & $8 \pm 0$ & $8 \pm 0$ & $\mathrm{~T}: \leq 0.05 \mathrm{ED}>\mathrm{CON}$ \\
\hline Awakenings longer than $60 \mathrm{~s}(\mathrm{f} / \mathrm{h})$ & $4 \pm 0$ & $4 \pm 0$ & $4 \pm 0$ & $4 \pm 0$ & \\
\hline REM latency (min) & $25 \pm 6$ & $36 \pm 8$ & $40 \pm 4$ & $41 \pm 5$ & $\mathrm{~A}:<0.05 \mathrm{Age}^{\mathrm{a}}<\mathrm{Age}^{\mathrm{b}}$ \\
\hline SWS latency (min) & $7 \pm 2$ & $5 \pm 2$ & $8 \pm 2$ & $19 \pm 6$ & $\mathrm{~T}:<0.05 \mathrm{ED}<\mathrm{CON}$ \\
\hline Number of REM periods & $22 \pm 1$ & $21 \pm 2$ & $25 \pm 1$ & $22 \pm 2$ & \\
\hline
\end{tabular}

Results are presented as mean $\pm \mathrm{SEM} ; p$ value is only stated for $p<0.1$ or else for the effect with the lowest value

$R E M$ rapid eye movement, $S W S$ slow-wave sleep, $S S T$ sleep stage transitions, $f / h$ frequency per hour, $A$ main effect of age, $T$ main effect of postnatal treatment

a $17-22$ weeks

b 22-26 weeks

latency in ED subjects is somewhat surprising as it indicates that, following sleep onset, the ED marmosets underwent a shorter interval before entering a first deep sleep period, which is associated with trophotropic, homeostatic, and restorative properties (Armitage and Hoffmann 2001; Nofinzger et al. 1999). To the best of our knowledge, there is no report of reduced SWS latency in depression, whereas reduction in amount of slow-wave sleep is one of the most robust sleep abnormalities in depression (Borbély et al. 1984; Kupfer 1995; Nofinzger et al. 1999).

Sleep studies in juveniles and adolescents with depression have yielded variable results to-date and it is unclear whether the same sleep abnormalities pertain as those described for depression in adulthood. Thus, although adolescents report subjective complaints about sleep similar to depressed adults, EEG studies have been inconsistent with respect to replicating the major adult findings, such as reduced REM latency, decreased slow-wave sleep, and reduced sleep efficiency (Dahl et al. 1991; Williamson et al. 1995). There are reports of increased sleep latency, reduced REM latency, and decreased sleep efficiency in depressed adolescents (Carskadon 2002; Dahl et al. 1996). Given that sleep-EEG is proposed to be modulated by HPA function via its modulation of brain centres responsible for circadian sleep rhythmicity and arousal (Steiger 2002), then it is interesting that the overall evidence is for ED chronic effects on HPA function and sleep-EEG, although this was not studied in the same subjects.

\section{Discussion}

The studies, some previously published and some original, that we have presented in this paper have as a common theme the impact of perinatal events that activate the glucocorticoid receptor, either specifically or in conjunction with other stress responses, on birth-to-adolescent development of HPA function, behaviour and molecular neuroanatomy in the two monkey species that are most studied in research laboratories, the rhesus macaque and common marmoset. By presenting these studies together we have aimed to provide a concise overview of our contributions to the experimental evidence for these inter-relationships in monkeys. Although the amount of primate evidence available is small compared with the rodent evidence, this overview should nonetheless be timely and useful, in that it provides a bridging reference between the rodent data - and the emphasis typically placed on this when extrapolating from experimental animal studies to descriptive human studies - and the human data. As emphasised in the "Introduction", given that our studies deal with the effects of different manipulations, experienced at different developmental time points, to some extent on different endpoints, and in different species, then the meaningful integration of the evidence obtained to yield emergent general conclusions is limited. Nonetheless, some meaningful general deductions can be made and these are presented below. With respect to the HPA axis, in the rhesus macaque, prenatal stress led to a chronic increase in 
basal cortisol titres and a chronic decrease in DEX suppression of cortisol. In rat, there is no consistent evidence that prenatal stress leads to altered basal cortisol levels (Weinstock 2005). In human, when low birth weight is used as an indicator of prenatal stress, there is no evidence for an association between birth weight and adulthood basal cortisol levels (Phillips 2007). Integrating this comparative evidence, the marked effect of prenatal stress on offspring basal cortisol levels that we observed in the rhesus macaque suggests that the stressor used was more severe than that typically experienced by humans in studies such as those where low birth weight is used as an indicator of prenatal stress. In the common marmoset, there was no postnatal effect of prenatal DEX on basal ACTH or cortisol levels. In rat, we have provided evidence that prenatal DEX leads to reduced basal cortisol titres in adult offspring (Hauser et al. 2009). In human, there is evidence that prenatal glucocorticoid exposure results in reduced basal cortisol levels in the neonate and infant in about one third of those studies conducted, with the remainder reporting no effect (Tegethoff et al. 2009). Therefore, the lack of an effect of prenatal DEX on offspring cortisol levels in common marmoset is in line with the majority of human studies; nonetheless, there is human and rat evidence that prenatal DEX can lead to reduced basal cortisol, and dose, dose-longevity and species-sensitivity could be determining factors. In marmoset, infants exposed to ED exhibited an increase in basal cortisol levels throughout the period of ED, and levels had returned to typical marmoset basal levels by late infancy. In rat, there is no evidence that postnatal pup-dam manipulations lead to altered basal cortisol levels in offspring (e.g. Ladd et al. 2004; Plotsky and Meaney 1993a). Human infants exposed to neglect or abuse within parental relationships exhibit relatively high basal cortisol levels (Gunnar and Quevedo 2007). Thus, the increase in basal cortisol levels in ED infant marmosets is in line with the evidence from human infants living in unstable family relationships; the subsequent recovery of basal cortisol levels in ED marmosets suggests that their social relationships in their family groups stabilised after the daily ED procedure had ceased. In the marmoset, ED also resulted in a chronic increase in the stressor reactivity of the HPA axis, in terms of the delta response to a (painful) saline injection in adolescent subjects. There is extensive evidence for the adult rat that maternal separation leads to increased HPA reactivity to stressors e.g. the psychophysical stressor of airpuff startle (Ladd et al. 2004). In humans, as for basal cortisol, ongoing or a history of instability in parental relationships in, respectively, infants/children or adolescents, predict increased cortisol responses to physical and social stressors (Gunnar and Quevedo 2007). Therefore, with respect to early life unpredictability in the infant-caregiver relation- ship, there is consistent evidence for rat, common marmoset and human that this leads to a chronic increase in HPA stressor reactivity.

With respect to behaviour, the reduced exploration exhibited by rhesus macaques suggests that prenatal stress resulted in increased anxiety. There is considerable evidence for the rat that prenatal stress leads in adulthood to increased anxiety, impaired coping with aversive stimuli and reduced interest in palatable stimuli (Weinstock 2005). In human, there is evidence for an association between prenatal stress and offspring anxiety; however, it is often the case that women who report stress during pregnancy are also stressed during offspring development, rendering it difficult to assign causality to the association prenatal stress-offspring anxiety (Phillips 2007). In common marmoset, we did not investigate the effects of prenatal DEX on anxiety behaviour. In rat, prenatal DEX has been reported to lead to increased anxiety behaviour in adult offspring (Hauser et al. 2009). In terms of the effects of ED on anxiety behaviour in common marmoset, we observed increased immobility and reduced contact calling in juvenile ED marmosets relative to their CON siblings following social isolation in a novel environment, which we interpret as an anxiogenic effect of ED (Dettling et al. 2007). Therefore, there is fairly consistent comparative evidence that each of the perinatal factors studied exerts long-term effects on emotional processing of the approachavoidance conflict situations that can elicit anxiety.

In the common marmoset, both prenatal DEX and ED exerted a number of effects on behaviour and across a number of domains. Both manipulations reduced time spent in social play as juveniles. Social play is, in terms of time spent in the activity and the opportunity it provides for social learning, a fundamentally important activity in primates. Its reduction by prenatal DEX and ED would be expected to impact on emotional and cognitive development, thereby constituting an additional pathway via which these perinatal insults can impact on development additional to their direct effects on the CNS.

With respect to neuroanatomical factors, in the rhesus macaque, prenatal stress led to reduced hippocampal neurogenesis and volume, as measured at adolescence. These cellular and structural changes in the hippocampus could have contributed to both the endocrine and behavioural effects observed in these adolescent prenatally stressed macaques. Mineralocorticoid receptors (MR) in the hippocampus are a major regulator of basal HPA activity and if reduced MR levels were a consequence of reduced hippocampal neurogenesis/volume then reduced proactive negative feedback by cortisol, leading to increased basal cortisol levels, would be predicted. Anxiety behaviour is, largely through bi-directional amygdala interaction, hippocampus-dependent (Gray and McNaughton 2000) 
and long-term cellular/structural changes could increase approach-avoidance conflict in anxiogenic situations. In the common marmoset, we did measure the effects of ED on MR expression, as well as on expression of GR and 5$\mathrm{HT}_{1 \mathrm{~A}}$. Both MR and GR expression were mildly reduced in adolescent ED marmosets relative to controls, and this was the case in the hippocampus specifically. These reductions occurred in the absence of any concomitant change in either basal cortisol levels (Dettling et al. 2007) or hippocampal volume (Law et al. 2009b), the latter suggesting that chronically reduced neurogenesis was not induced in ED marmosets. Clearly it will be very important to investigate the impact of prenatal DEX and prenatal and postnatal stress on hippocampal MR and GR expression in the rhesus macaque in future studies.

The common marmoset exhibits relative glucocorticoid insensitivity, and this trait is clearly relevant to the present overview as well as to a general assessment of the suitability of this primate as a "model species" for the study of the effects of perinatal DEX exposure or social stress and the extrapolation of findings in this species to others, most obviously the human. Based on both the endogenous biology of the common marmoset and related species, and the findings of the current studies, we would argue that the common marmoset is a suitable model species and findings attained with it can be extrapolated to human, with some caveats. Thus, with respect to endogenous HPA function, the common marmoset exhibits typical mammalian traits such as a circadian rhythm in basal circulating ACTH and cortisol levels and an acute elevation in ACTH and cortisol levels in response to physical and social stress (Pryce et al. 2002). The common marmoset is different from the rhesus macaque and human in terms of infancy being a life stage characterised by basal hypercortisolism relative to older life stages (there are currently no data on cortisol levels in the foetal common marmoset). In postnatal week 1, cortisol levels are an order of magnitude greater than at any older life stage, and this appears to be the combined outcome of relatively high ACTH levels, an active foetal zone in the adrenal gland and immaturity of the cortisol metabolism/excretion system in these 1-week-old common marmosets (Pryce et al. 2002). In the rhesus macaque, there is a slight decrease in ACTH and cortisol levels across months 1-6 (Clarke 1993), and in the human cortisol levels increase gradually to adult-like levels between week 1 and month 3 (Spangler 1991). Interestingly, young infant common marmosets share the human neonate characteristic of absence of a circadian rhythm in cortisol levels (Pryce et al. 2002). Although the molecular basis of glucocorticoid insensitivity has not been studied directly in the common marmoset, in the closely related squirrel monkey, which also exhibits glucocorticoid insensitivity, it has been demonstrated that glucocorticoid resistance results from a combination of a transcriptionally incompetent GR and, in particular, over-expression of the protein FKBP51, a co-chaperone in the protein complex that regulates GR affinity to its ligand cortisol (Westberry et al. 2006). Therefore, it would appear that in the common marmoset, the endogenous "dose-response curve" of GR activation is shifted to the right relative to other taxa, that the endogenous levels of basal and stress cortisol are increased accordingly, and greater masses of exogenous ligands e.g. DEX yield the same effect as lesser masses in other taxa. That is, the common marmoset is speciesatypical in a quantitative but not a qualitative way with respect to its GR-ligand system. However, with respect to the effects of postnatal manipulations, such as ED, the common marmoset would appear to be species-atypical in both a quantitative and qualitative way, given that the trait of infantile hyper-cortisolism exerts a floor effect on the magnitude of the cortisol stress response, particularly in young infants and in the morning, such that stress-induced hyper-cortisolism might be expected to be less pronounced and therefore to exert less cellular and molecular effects than in other primate species. If this argument is accepted, then the moderate but consistent long-term effects of ED on physiology, behaviour and neuroanatomy in the common marmoset become really quite striking.

In summary, this overview of our published and some original studies presents evidence for enduring effects of specific perinatal stress-related manipulations in the rhesus macaque and the common marmoset, with some consistency across manipulations and species. In terms of HPA function, the evidence is for increased basal cortisol in adolescent rhesus macaques following prenatal stress and a prolonged cortisol stress response in adolescent marmosets following repeated parental separation. In terms of behaviour, exploration was reduced in adolescent macaques, and social play motivation was reduced in infant-juvenile marmosets following prenatal DEX exposure or repeated parental separation. In terms of neuroanatomy, hippocampal neurogenesis and volume were reduced in adolescent macaques following prenatal stress, and hippocampal expression of the genes for MR, GR and 5-HT1A were reduced in adolescent marmosets exposed to repeated parental separation. The mechanisms mediating these enduring effects remain to be elucidated, with candidates including reduced neurogenesis or gliogenesis in hippocampus and other brain regions, mediated in part by acute increases in MR and/or GR binding in the foetus or infant, and long-term changes in gene expression due to epigenetic programming.

Acknowledgements We are extremely grateful to Christina Schlumbohm, Christopher Coe, Marian Kramer, Boldizsár Czéh, Joram Feldon, Andrea Dettling, Jonas Hauser, Sonia Pilloud, Marianne Spengler, Alana Knapman, Else-Marie Pedersen, Corinne Spaete, Jeanne 
Michel, Irene Knuesel, Elizabeth Weber, Dimitrula Arabadzisz, Amanda Law, Paul Harrison and Rochellys Diaz-Heijtz for their substantial contributions and support. The work summarised in this article was supported by grants from the European Union (QLRT-2001-02758, EUPEAH), the Gustav Adolf Lienert-Siftung für die Nachwuchsförderung in Biopsychologischer Methodik, and the Swiss National Science Foundation (310030-110010).

Animal experiments were conducted in accordance with the European Communities' Council Directive of November 24, 1986, and were approved by the Lower Saxony Federal State Office for Consumer Protection and Food Safety and the Cantonal Veterinary Office Zurich.

The authors declare no competing financial interests.

Open Access This article is distributed under the terms of the Creative Commons Attribution Noncommercial License which permits any noncommercial use, distribution, and reproduction in any medium, provided the original author(s) and source are credited.

\section{References}

Arabadzisz D, Diaz-Heijtz R, Knuesel I, Weber E, Pilloud S, Dettling AC, Feldon J, Law AJ, Harrison PJ, Pryce CR (2010) Primate early life stress leads to long-term mild hippocampal decreases in corticosteroid receptor expression. Biol Psychiatry 67(11):1106-1109

Armitage R, Hoffmann RF (2001) Sleep EEG, depression and gender. Sleep Med Rev 5:237-246

Aubert Y (2004) Effects of early life stress on ECoG-defined sleep patterns in the common marmoset monkey biology department. Swiss Federal Institute of Technology Zürich, Zürich

Avishai-Eliner S, Brunson KL, Sandman CA, Baram TZ (2002) Stressed-out, or in (utero)? Trends Neurosci 25:518-524

Benca RM, Obermeyer WH, Thisted RA, Gillin JC (1992) Sleep and psychiatric disorders - a meta-analysis. Arch Gen Psychiatry 49:651-668

Borbély AA, Tobler I, Loepfe M (1984) All-night spectral analysis of the sleep EEG in untreated depressives and normal controls. Psychiatry Res 12:27-33

Bremner JD, Narayan M, Anderson ER, Staib LH, Miller HL, Charney DS (2000) Hippocampal volume reduction in major depression. Am J Psychiatry 157:115-118

Brown AS, van Os J, Driessens C, Hoek HW, Susser ES (2000) Further evidence of relation between prenatal famine and major affective disorder. Am J Psychiatry 157:190-195

Buwalda B, de Boer SF, Schmidt ED, Felszeghy K, Nyakas C, Sgoifo A, Van der Vegt BJ, Tilders FJ, Bohus B, Koolhaas JM (1999) Long-lasting deficient dexamethasone suppression of hypothalamic-pituitary-adrenaocortical activation following peripheral CRF challenge in socially defeated rats. J Neuroendocrinol 11:513-520

Carskadon MA (2002) Adolescent sleep patterns: biological, social, and psychological influences. Cambridge University Press, London

Clancy KB (2009) Reproductive ecology and the endometrium: physiology, variation, and new directions. Am J Phys Anthropol 140(Suppl):137-154

Clarke AS (1993) Social rearing effects on HPA axis activity over early development and in response to stress in rhesus monkeys. Dev Psychobiol 26:433-446

Clarke AS, Schneider ML (1993) Prenatal stress has long-term effects on behavioral responses to stress in juvenile rhesus monkeys. Dev Psychobiol 26:293-304

Clements A (1992) The incidence of attention deficit-hyperactivity disorder in children whose mothers experienced extreme psychological stress. Dev Psychobiol 41:178-185
Coe CL, Lulbach GR, Schneider ML (2002) Prenatal disturbance alters the size of the corpus callosum in young monkeys. Dev Psychobiol 41:178-185

Coe CL, Kramer M, Czeh B, Gould E, Reeves AJ, Kirschbaum C, Fuchs E (2003) Prenatal stress diminishes neurogenesis in the dentate gyrus of juvenile rhesus monkeys. Biol Psychiatry 54:1025-1034

Crowley P (2000) Prophylactic corticosteroids for preterm birth. Cochrane Database Syst Rev 2:CD000065

Czeh B, Michaelis T, Watanabe T, Frahm J, de Biurrun G, van Kampen M, Bartolomucci A, Fuchs E (2001) Stress-induced changes in cerebral metabolites, hippocampal volume, and cell proliferation are prevented by antidepressant treatment with tianeptine. Proc Natl Acad Sci USA 98:12796-12801

Dahl RE, Ryan ND, Birmaher B, Al-Shabbout M (1991) Electroencephalographic sleep measures in prepubertal depression. Psychiatry Res 38:201-214

Dahl RE, Ryan ND, Matty MK, Birmaher B, Al-Shabbout M, Williamson DE, Kupfer DJ (1996) Sleep onset abnormalities in depressed adolescents. Biol Psychiatry 39:400-410

De Kloet ER, Vreugdenhil E, Oitzl MS, Joels M (1998) Brain corticosteroid receptor balance in health and disease. Endocr Rev 19:269-301

Dettling AC, Feldon J, Pryce CR (2002) Repeated parental deprivation in the infant common marmoset (Callithrix jacchus, Primates) and analysis of its effects on early development. Biol Psychiatry 52:1037-1046

Dettling AC, Schnell CR, Maier C, Feldon J, Pryce CR (2007) Behavioral and physiological effects of an infant-neglect manipulation in a bi-parental, twinning primate: impact is dependent on familial factors. Psychoneuroendocrinology 32:331-349

Diaz Heijtz R, Fuchs E, Feldon J, Pryce CR, Forssberg H (2010) Effects of antenatal dexamethasone treatment on glucocorticoid receptor and calcyon gene expression in the prefrontal cortex of neonatal and adult common marmoset monkeys. Behav Brain Funct 6:18

Dodic M, Hantzis V, Duncan J, Rees S, Koukoulas I, Johnson K, Wintour EM, Moritz K (2002) Programming effects of short prenatal exposure to cortisol. FASEB J 16:1017-1026

DSM-IV (1994) Diagnostic and Statistical Manual of Mental Disorders. 4th edn. American Psychiatric Association, Washington, DC

Elliot MG, Crespi BJ (2008) Placental invasiveness and brain-body allometry in eutherian mammals. J Evol Biol 21:1763-1778

Fuchs E, Flugge G, Czeh B (2006) Remodeling of neuronal networks by stress. Front Biosci 11:2746-2758

Fujii EY, Takahashi N, Kodama Y, Roman C, Ferriero DM, Parer JT (2003) Hemodynamic changes during complete umbilical cord occlusion in fetal sheep related to hippocampal neuronal damage. Am J Obstet Gynecol 188:413-418

Gilbertson MW, Shenton ME, Ciszewski A, Kasai K, Lasko NB, Orr SP, Pitman RK (2002) Smaller hippocampal volume predicts pathologic vulnerability to psychological trauma. Nat Neurosci 5:1242-1247

Gray JA, McNaughton N (2000) The neuropsychology of anxiety. Oxford University Press, Oxford

Gunnar MR (1992) Reactivity of the hypothalamic-pituitaryadrenocortical system to stressors in normal infants and children. Pediatrics 90:491-497

Gunnar M, Quevedo K (2007) The neurobiology of stress and development. Annu Rev Psychol 58:145-173

Gur RE, Turetsky BI, Cowell PE, Finkelman C, Maany V, Grossman RI, Arnold SE, Bilker WB, Gur RC (2000) Temporolimbic volume reductions in schizophrenia. Arch Gen Psychiatry 57:769-775

Hauser J, Dettling-Artho AC, Pilloud S, Maier C, Knapman A, Feldon J, Pryce CR (2007) Effects of prenatal dexamethasone treatment 
on postnatal physical, endocrine, and social development in the common marmoset moneky. Endocrinology 148:1813-1822

Hauser J, Knapman A, Zürcher NR, Pilloud S, Maier C, Diaz-Heijtz R, Forssberg H, Dettling A, Feldon J, Pryce CR (2008) Effects of prenatal dexamethasone treatment on physical growth, pituitaryadrenal hormones, and performance of motor, motivational, and cognitive tasks in juvenile and adolescent common marmoset monkeys. Endocrinology 149:6343-6355

Hauser J, Feldon J, Pryce CR (2009) Direct and dam-mediated effects of prenatal dexamethasone on emotionality, cognition and HPA axis in adult Wistar rats. Horm Behav 56:364-375

Hearn JP, Burden FJ (1979) 'Collaborative' rearing of marmoset triplets. Lab Anim 13:131-133

Heijtz RD, Alexeyenko A, Castellanos FX (2007) Calcyon mRNA expression in the frontal-striatal circuitry and its relationship to vesicular processes and ADHD. Behav Brain Funct 3:33

Heim C, Plotsky PM, Nemeroff CB (2004) Importance of studying the contributions of early adverse experience to neurobiological findings in depression. Neuropsychopharmacol 29:641648

Heuser I, Yassouridis A, Holsboer F (1994) The combined dexamethasone/ CRH test: a refined laboratory test for psychiatric disorders. J Psychiatr Res 28:341-356

Huttunen MO, Niskanen P (1978) Prenatal loss of father and psychiatric disorders. Arch Gen Psychiatry 35:429-431

Johnson EO, Kamilaris TC, Carter CS, Calogero AE, Gold PW, Chrousos GP (1996) The biobehavioral consequences of psychogenic stress in a small, social primate (Callithrix jacchus). Biol Psychiatry 40:317-337

Kendler KS, Gardner CO, Prescott CA (2002) Toward a comprehensive development model for major depression in women. Am J Psychiatry 159:1133-1145

Koehl M, Darnaudery M, Dulluc J, Van Reeth O, Le Moal M, Maccari S (1999) Prenatal stress alters circadian activity of hypothalamopituitary-adrenal axis and hippocampal corticosteroid receptors in adult rats of both gender. J Neurobiol 40:302-315

Kupfer DJ (1995) Sleep research in depressive illness: clinical implications - a tasting menu. Biol Psychiatry 38:391-403

Ladd CO, Huot RL, Thrivikraman KV, Nemeroff CB, Plotsky PM (2004) Long-term adaptations in glucocorticoid receptor and mineralocorticoid receptor mRNA and negative feedback on the hypothalamo-pituitary-adrenal axis following neonatal maternal separation. Biol Psychiatry 55:367-375

Law AJ, Pei Q, Feldon J, Pryce CR, Harrison PJ (2009a) Gene expression in the anterior cingulate cortex and amygdala of adolescent marmoset monkeys following parental separations in infancy. Int J Neuropsychopharmacol 12:761-772

Law AJ, Pei Q, Walker M, Gordon-Andrews H, Weickert CS, Feldon J, Pryce CR, Harrison PJ (2009b) Early parental deprivation in the marmoset monkey produces long-term changes in hippocampal expression of genes invloved in synaptic plasticity and implicated in mood disorder. Neuropsychopharmacol 34:1381-1394

Lemaire V, Koehl M, Le Moal M, Abrous DN (2000) Prenatal stress produces learning deficits associated with an inhibition of neurogenesis in the hippocampus. Proc Natl Acad Sci USA 97:11032-11037

Levine S (1994) The ontogeny of the hypothalamic-pituitary-adrenal axis: the influence of maternal factors. Ann NY Acad Sci $746: 275-293$

Levine S (2002) Enduring effects of early experience on adult behavior. In: Pfaff DW, Arnold AP, Etgen AM, Fahrbach SE, Rubin RT (eds) Hormones, brain and behavior, vol 4. Academic, New York, pp 535-542

Levitt P (2003) Structural and functional maturation of the developing primate brain. J Pediatr 143:S35-S45
Lucassen PJ, Meerlo P, Naylor AS, van Dam AM, Dayer AG, Fuchs E, Oomen CA, Czeh B (2010) Regulation of adult neurogenesis by stress, sleep disruption, exercise and inflammation: Implications for depression and antidepressant action. Eur Neuropsychopharmacol 20:1-17

Lupien S, McEwen BS, Gunnar MR, Heim C (2009) Effects of stress throughout the lifespan on the brain, behaviour and cognition. Nat Rev Neurosci 10:434-445

Maier C (2003) The effects of early life stress on the neurobiological status of infant common marmosets biology departement. Swiss Federal Institute of Technology Zürich, Zürich

Martin RD (1990) Primate Origins and Evolution: a phylogenetic approach. Chapman \& Hall, London

McDonald C, Murray RM (2000) Early and late environmental factors for schizophernia. Brain Res Rev 31:130-137

McKenna JJ, Ball HL, Gettler LT (2007) Mother-infant cosleeping, breastfeeding and sudden infant death syndrome: what biological antrhopology has discovered about normal infant sleep and pediatric sleep medicine. Am J Phys Anthropol Suppl 45:133-161

Meaney MJ, Aitken DH, Sharma S, Viau V (1992) Basal ACTH, corticosterone and corticosterone-binding globulin levels over the diurnal cycle, and age-related changes in hippocampal type I and type II corticosteroid receptor binding capacity in young and aged, handled and nonhandled rats. Neuroendocrinology 55:204-213

Michaelis T, Abaei A, Boretius S, Tammer R, Frahm J, Schlumbohm C, Fuchs E (2009) Intrauterine hyperexposure to dexamethasone of the common marmoset monkey revealed normal cerebral metabolite concentrations in adulthood as assessed by quantitative proton magnetic resonance spectroscopy in vivo. J Med Primatol 38:213-218

Myhrman A, Rantakallio P, Isohanni M, Jones P, Partanen U (1996) Unwantedness of a pregnancy and schizophrenia in the child. $\mathrm{Br}$ J Psychiatry 169:637-640

Nofinzger EA, Keshavan M, Buysse DJ, Moore RY, Kupfer DJ, Reynolds CF (1999) The neurobiology of sleep in relation to mental illness. In: Charney DS, Nestler EJ, Bunney BS (eds) Neurobiology of Mental Illness. Oxford University Press, New York, pp 121-131

Nyirenda MJ, Seckl JR (1998) Intrauterine events and the programming of adulthood disease: the role of fetal glucocorticoid exposure (Review). Int J Mol Med 2:607-614

Pearce PC, Crofts HS, Muggleton NG, Scott EAM (1997) Concurrent monitoring of EEG and performance in the common marmoset: a methodological approach. Physiol Behav 63:591-599

Pervanidou P, Chrousos GP (2007) Post-traumatic stress disorder in children and adolescents: from Sigmund Freud's "trauma" to psychopathology and the (dys)metabolic syndrome. Horm Metab Res 39:413-419

Phillips DI (2007) Programming of the stress response: a fundamental mechanism underlying the long-term effects of the fetal environment? J Intern Med 261:453-460

Plotsky PM, Meaney MJ (1993a) Early, postnatal experience alters hypothalamic corticotropin-releasing factor (CRF) mRNA, median eminence CRF content and stress-induced release in adult rats. Mol Brain Res 18:195-200

Plotsky PM, Meaney MJ (1993b) Early, postnatal experience alters hypothalamic corticotropin-releasing factor (CRF) mRNA, median eminence CRF content and stress-induced release in adult rats. Brain Res Mol Brain Res 18:195-200

Pryce CR, Feldon J (2003) Long-term neurobehavioral impact of the postnatal environment in rats: manipulations, effects and mediating mechanisms. Neurosci Biobehav Rev 27:57-71

Pryce CR, Bettschen D, Feldon J (2001) Comparison of the effects of early handling and early deprivation on maternal care in the rat. Dev Psychobiol 38:239-251 
Pryce CR, Palme R, Feldon J (2002) Development of pituitary-adrenal endocrine function in the marmoset monkey: infant hypercortisolism is the norm. JCEM 87:691-699

Pryce CR, Dettling AC, Feldon J (2004a) Evidence for altered monoamine activity and emotional and cognitive disturbance in marmoset monkeys exposed to early life stress. Ann NY Acad Sci 1032:245-249

Pryce CR, Dettling AC, Spengler M, Schnell CR, Feldon J (2004b) Deprivation of parenting disrupts development of homeostatic and reward systems in marmoset monkey offspring. Biol Psychiatry 56:72-79

Pryce CR, Ruedi-Bettschen D, Dettling AC, Weston A, Russig H, Ferger B, Feldon J (2005) Long-term effects of early-life environmental manipulations in rodents and primates: potential animal models in depression research. Neurosci Biobehav Rev 29:649-674

Rechtschaffen A, Kales A (1968) A manual of standarized terminology, techniques and scoring system for sleep stages of human subjects. $\mathrm{NIH}$, Bethesda

Rees S, Breen S, Loeliger M, McCrabb G, Harding R (1999) Hypoxemia near mid-gestation has long-term effects on fetal brain development. J Neuropathol Exp Neurol 58:932-945

Rice F, Harold GT, Boivin J, van den Bree M, Hay DF, Thapar A (2010) The links between prenatal stress and offspring development and psychopathology: disentangling environmental and inherited influences. Psychol Med 40:335-345

Ruppenthal GC, Arling GL, Harlow HF, Sackett GP, Suomi SJ (1976) A 10-year perspective pf motherless-mother monkey behavior. J Abnorm Psychol 85:341-349

Saltzman W, Prudom SL, Schultz-Darken N, Wittwer DJ, Abbott DH (2004) Social suppression of cortisol in female marmoset monkeys: role of circulating ACTH levels and glucocorticoid negative feedback. Psychoneuroendocrinology 29:141-161

Schneider ML, Roughton EC, Koehler AJ, Lubach GR (1999) Growth and development following prenatal stress exposure in primates: an examination of ontogenetic vulnerability. Child Dev 70:263274

Seckl JR (1997) Glucocorticoids, feto-placental 11 beta-hydroxysteroid dehydrogenase type 2 , and the early life origins of adult disease. Steroids 62:89-94

Seckl JR (2004) Prenatal glucocorticoids and long-term programming. Eur J Endocrinol 151(Suppl 3):U49-U62

Seckl JR (2008) Glucocorticoids, developmental 'programming' and the risk of affective dysfunction. Prog Brain Res 167:17-34

Shors TJ, Miesegaes G, Beylin A, Zhao M, Rydel T, Gould E (2001) Neurogenesis in the adult is involved in the formation of trace memories. Nature 410:372-376

Shors TJ, Townsend DA, Zhao M, Kozorovitskiy Y, Gould E (2002) Neurogenesis may relate to some but not all types of hippocampal-dependent learning. Hippocampus 12:578-584

Spangler G (1991) The emergence of adrenocortical circadian function in newborns and infants and its relationship to sleep, feeding and maternal adrenocortical activity. Early Hum Dev 25:197-208
Steiger A (2002) Sleep and the hypothalamo-pituitary-adrenocortical system. Sleep Med Rev 6:125-138

Suchecki D, Rosenfeld P, Levine S (1993) Maternal regulation of the hypothalamic-pituitary-adrenal axis in the infant rat: the roles of feeding and stroking. Dev Brain Res 75:185-192

Takahashi LK (1998) Prenatal stress: consequences of glucocorticoids on hippocampal development and function. Int J Dev Neurosci 16:199-207

Talge NM, Neal C, Glover V, Health ESTRaPSNFaNEoCaAM (2007) Antenatal maternal stress and long-term effects on child neurodevelopment: how and why? J Child Psychol Psychiatry 48:245-261

Tauber SC, Schlumbohm C, Schilg L, Fuchs E, Nau R, Gerber J (2006) Intrauterine exposure to dexamethasone impairs proliferation but not neuronal differentiation in the dentate gyrus of newborn common marmoset monkeys. Brain Pathol 16:209-217

Tauber SC, Bunkowski S, Schlumbohm C, Ruhlmann M, Fuchs E, Nau R, Gerber J (2008) No long-term effect 2 years after intrauterine exposure to dexamethasone on dentate gyrus volume, neuronal proliferation and differentiation in common marmoset monkeys. Brain Pathol 18:497-503

Tegethoff M, Pryce C, Meinlschmidt G (2009) Effects of intrauterine exposure to synthetic glucocorticoids on fetal, newborn, and infant hypothalamic-pituitary-adrenal axis function in humans: a systematic review. Endocr Rev 30:753-789

Uno H, Lohmiller L, Thieme C, Kemnitz JW, Engle MJ, Roecker EB, Farrell PM (1990) Brain damage induced by prenatal exposure to dexamethasone in fetal rhesus macaques I. Hippocampus. Dev Brain Res 53:157-167

van Os J, Selten JP (1998) Prenatal exposure to maternal stress and subsequent schizophrenia. The May 1940 invasion of The Netherlands. Br J Psychiatry 172:324-326

Wadhwa PD, Sandman CA, Garite TJ (2001) The neurobiology of stress in human pregnancy: implications for prematurity and development of the fetal central nervous system. Prog Brain Res 133:131-142

Watson JB, Mednick SA, Huttunen M, Wang X (1999) Prenatal teratogens and the development of adult mental illness. Dev Psychopathol 11:457-466

Weaver ICG, Cervoni N, Champagne FA, D'Alessio AC, Sharma S, Seckl JR, Dymov S, Szyf M, Meaney MJ (2004) Epigenetic programming by maternal behavior. Nat Neurosci 7:847-854

Weinstock M (1997) Does prenatal stress impair coping and regulation of hypothalamic-pituitary-adrenal axis? Neurosci Biobehav Rev 21:1-10

Weinstock M (2005) The potential influence of maternal stress hormones on development and mental health of the offspring. Brain Behav Immun 19:296-308

Westberry JM, Sadosky PW, Hubler TR, Gross KL, Scammell JG (2006) Glucocorticoid resistance in squirrel monkeys results from a combination of a transcriptionally important glucocorticoid receptor and overexpression of the glucocortioid receptor co-chaperone FKBP51. J Steroid Biochem Mol Biol 100:34-41

Williamson DE, Dahl RE, Birmaher B, Goetz RR, Nelson BB, Ryan ND (1995) Stressful life events and EEG sleep in depressed and normal control adolescents. Biol Psychiatry 37:859-865 